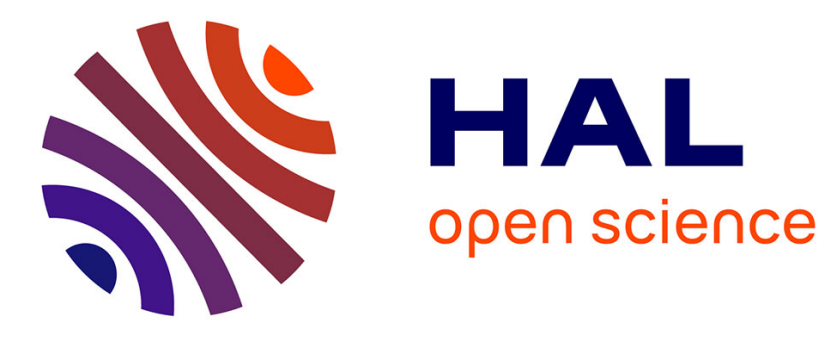

\title{
Extraction of metals with ABS
}

Isabelle Billard

\section{To cite this version:}

Isabelle Billard. Extraction of metals with ABS. Mara G. Freire. Ionic-liquid based aqueous biphasic systems: fundamentals and applications, Springer, pp.183-220, 2016, Green Chemistry and Sustainable Technology, 978-3-662-52875-4. 10.1007/978-3-662-52875-4_9 . hal-02272199

\section{HAL Id: hal-02272199 \\ https://hal.science/hal-02272199}

Submitted on 27 Aug 2019

HAL is a multi-disciplinary open access archive for the deposit and dissemination of scientific research documents, whether they are published or not. The documents may come from teaching and research institutions in France or abroad, or from public or private research centers.
L'archive ouverte pluridisciplinaire HAL, est destinée au dépôt et à la diffusion de documents scientifiques de niveau recherche, publiés ou non, émanant des établissements d'enseignement et de recherche français ou étrangers, des laboratoires publics ou privés. 


\title{
Extraction of metals with ABS
}

\author{
Isabelle Billard ${ }^{a, b}$ \\ aUniv. Grenoble Alpes, LEPMI, F-38000 Grenoble, France \\ ${ }^{b}$ CNRS, LEPMI, F-38000 Grenoble, France \\ Postal address: LEPMI, 1140, rue de la Piscine, 38402 Saint Martin d'Hères, France \\ $\underline{\text { Isabelle.billard@lepmi.grenoble-inp.fr }}$
}

\begin{abstract}
Extraction of metallic ions by use of mixtures of water and ILs, possibly completed by mineral acids, salts and/or extracting agents, and leading to ionic-liquid-aqueous biphasic systems (IL-ABS), are critically reviewed. In this chapter, the extraction performance induced by temperature or concentration stimulus is considered. First, the IL-ABS basic physico-chemical properties are recalled, highlighting those of interest to metal extraction. Then, the main results are presented and discussed for systems ordered and categorized by IL types. Various extensions of the notion of IL-ABS are given and briefly discussed as an advocacy in favor of a continuous line between "real" ABS comprising ILS and other liquid-liquid extraction systems including one IL.
\end{abstract}

Keywords: ionic liquids, metal extraction, aqueous biphasic systems

\subsection{Introduction}

Extraction of metals from aqueous phases is a huge problem connected to a large number of industrial applications: It is important not only for ore exploitation or for recycling of precious metals (found in "urban wastes" or in used nuclear fuels), but also in view of polluted waters characterization, to name a few. Furthermore, it concerns all metals, from $\mathrm{Cs}$ and $\mathrm{Sr}$ to $d$-elements, such as $\mathrm{Cu}, \mathrm{Co}, \mathrm{Ni}, \mathrm{Zn}, \mathrm{Pb}$ or $\mathrm{Hg}$, as well as $\mathrm{Au}, \mathrm{Pt}, \mathrm{Ir}$, lanthanides, and finally $5 f$-metals, such as $\mathrm{U}, \mathrm{Pu}$ or $\mathrm{Cm}$. Most of the time, the metal to be extracted is not the only element present in the aqueous feed, which often contains other metals and large amounts of mineral acids, such as nitric or hydrochloric acid, that have been used to dissolve the ores or the wastes to be recycled. As a consequence, metals in such aqueous acidified solutions exist as ions, either cations or anions, depending on their specific affinity towards the counter-anion of the acid and concentration of the latter. In the case of water depollution, samples may contain organic compounds, possibly bacteria or other biological entities that all may also complex metal ions. Needless to say, high extraction efficiencies and selectivity for the metal of interest are requested, together with cost-effectiveness, protocol easiness and limited operation times. To solve this problem, or better to say, these problems, liquid-liquid extraction has emerged years ago as the best industrial process ever [1], and since the industrial implementation of the PUREX process, first designed to extract $\mathrm{U}$ and $\mathrm{Pu}$ in the 1940's, liquid-liquid extraction of metals has successfully achieved all goals cited above.

Typical liquid-liquid extractions from aqueous phases are based on the use of volatile organic compounds (VOCs), such as chloroform, dichloromethane, kerosene etc., as the second liquid phase, 
and to which the metallic entities are extracted. Therefore, and in addition to costs linked to the design of always better extracting agents, one should consider, under the light of the European $\mathrm{REACH}$ regulation, for example, environmental costs. Under such a frame, liquid-liquid extraction is now looking for an ecologic revival.

After the work of Dai and co-workers [2] evidencing an increase up to four orders of magnitude in Sr(II) extraction efficiency by replacing traditional solvents by some ionic liquids (ILS), these new solvents have offered fantastic opportunities as VOCs' replacements in view of liquid-liquid extraction of metals, and there are now numerous academic studies that have demonstrated their advantages in terms of extraction efficiency of metals [3-5], and one critical review [6]. Interestingly enough, ILs have also rapidly proved to provide even better uses than mere VOCs replacement solvents. Actually, they can also act as pure liquid phases, i.e., without the use of any additional extracting agent as usually needed when using molecular solvents. Depending on systems and metals, such a surprising result can be obtained either with very simple and "classical" (i.e. commercially available) ILs [4] or with specifically synthesized ILs, the so-called Task-Specific ILs (TSILS), bearing complexing patterns such as phosphine oxide, amides, crow-ether or calixarenes [711]. Such innovative liquid-liquid extraction procedures, however, correspond to higher costs, renewed synthetic studies and collateral problems linked to the high viscosity of ILs among other problems.

In parallel to these evolutions of liquid-liquid extraction studies and practices, and in a rather disconnected way, the academic community has developed and brought to industrial applications the concept of aqueous biphasic systems (ABS), mainly for extraction/separation of biological molecules and a large variety of compounds (see other chapters of this book on this point). Although it may now appear evident that the use of ABS is not restricted to organic or biological samples, the idea of bringing the knowledge gained on ILS and on ABS in view of metal extraction has emerged only quite recently. To our opinion, this field of research will soon blossom and the rather limited number of papers available at the moment is just the beginning of a topic soon to expand tremendously.

In this chapter, section 9.2 is devoted to notations and definitions of ILs and IL-based ABS concepts. Properties of IL-based ABS of interest to metal extraction are also recalled and discussed in details. Next, in section 9.3, papers on metal extraction by IL-ABS are critically reviewed. Literature is ordered based on IL types and not on the type of metal being extracted; however, the reader can find in Table 9.1 a summary where the key entrance is metallic elements. For each case, we first recall why the system under review falls in the scope of the chapter and we thereafter present and discuss the extraction results and other data of relevance to the understanding of the fascinating IL-based ABS. Section 9.4, by gathering data dealing with systems close to IL-based ABS, hopefully demonstrates to the reader that there is actually a continuous line linking all these systems. 
Table 9.1. List of the metallic ions extracted by use of IL-ABS. Elements are listed in alphabetical order and are displayed if $D_{x, e}$ is $\geq 1$.

\begin{tabular}{|c|c|c|}
\hline Metal, oxidation number & IL-ABS & ref. \\
\hline $\mathrm{Ag}(\mathrm{I})$ & $\begin{array}{l}\mathrm{H}_{2} \mathrm{O} \&\left[\mathrm{C}_{1} \mathrm{C}_{6} \mathrm{im}^{+}\right]\left[\mathrm{BF}_{4}^{-}\right] \&\left[\mathrm{Na}^{+}\right]\left[\mathrm{PF}_{6}^{-}\right] \&\left[\mathrm{H}^{+}\right]\left[\mathrm{NO}_{3}^{-}\right] \\
\mathrm{H}_{2} \mathrm{O} \&\left[\mathrm{C}_{1} \mathrm{C}_{4} \mathrm{im}^{+}\right]\left[\mathrm{Cl}{ }^{-}\right] \&\left[\mathrm{H}^{+}\right]\left[\mathrm{NO}_{3}^{-}\right] \&\left[\mathrm{~K}^{+}\right]_{2}\left[\mathrm{HPO}_{4}^{2-}\right]\end{array}$ & $\begin{array}{l}12] \\
{[13]}\end{array}$ \\
\hline $\mathrm{Au}(\mathrm{III})$ & $\begin{array}{l}\mathrm{H}_{2} \mathrm{O} \&\left[\mathrm{C}_{1} \mathrm{C}_{8} \mathrm{im}^{+}\right]\left[\mathrm{Cl}^{-}\right] \&\left[\mathrm{H}^{+}\right]\left[\mathrm{Cl}^{-}\right] \\
\mathrm{H}_{2} \mathrm{O} \&\left[\mathrm{C}_{1} \mathrm{C}_{8} \mathrm{im}^{+}\right][\mathrm{Br}] \&\left[\mathrm{H}^{+}\right][\mathrm{Br}] \\
\mathrm{H}_{2} \mathrm{O} \&\left[\mathrm{C}_{8} \mathrm{pyr}^{+}\right][\mathrm{Br}] \&\left[\mathrm{H}^{+}\right][\mathrm{Br}]\end{array}$ & $\begin{array}{l}{[14]} \\
{[14]} \\
{[14]}\end{array}$ \\
\hline $\mathrm{Ce}(\mathrm{IV})$ & $\mathrm{H}_{2} \mathrm{O} \&\left[\mathrm{C}_{1} \mathrm{C}_{8} \mathrm{im}^{+}\right]\left[\mathrm{Cl}^{-}\right] \&\left[\mathrm{H}^{+}\right]\left[\mathrm{NO}_{3}^{-}\right]$ & [15] \\
\hline $\mathrm{Cd}(\mathrm{II})$ & $\mathrm{H}_{2} \mathrm{O} \&\left[\mathrm{TBA}^{-}\right]\left[\mathrm{Br}^{-}\right] \&\left[\mathrm{NH}_{4}^{+}\right]_{2}\left[\mathrm{SO}_{4}{ }^{2-}\right]$ & [16] \\
\hline $\mathrm{Co}(\mathrm{II})$ & $\begin{array}{l}\mathrm{H}_{2} \mathrm{O} \& \text { Girard-IL } \\
\mathrm{H}_{2} \mathrm{O} \&\left[\mathrm{P}_{444} \mathrm{E}_{\mathrm{i}}^{+}\right][\mathrm{DEHP}](\mathrm{i}=1,2,3)\end{array}$ & $\begin{array}{l}{[17]} \\
{[18]}\end{array}$ \\
\hline $\mathrm{Cr}(\mathrm{III})$ & $\mathrm{H}_{2} \mathrm{O} \&$ Girard-IL & {$[17]$} \\
\hline $\mathrm{Cr}(\mathrm{IV})$ & $\mathrm{H}_{2} \mathrm{O} \&\left[\mathrm{TBA}^{-}\right]\left[\mathrm{Br}^{-}\right] \& 2\left[\mathrm{NH}_{4}{ }^{+}\right]\left[\mathrm{SO}_{4}{ }^{2-}\right]$ & [19] \\
\hline $\mathrm{Cu}(\mathrm{II})$ & $\begin{array}{l}\mathrm{H}_{2} \mathrm{O} \&\left[\text { Hbet }^{+}\right]\left[\mathrm{Tf}_{2} \mathrm{~N}^{-}\right] \& \text { bet } \\
\mathrm{H}_{2} \mathrm{O} \& \text { Girard-IL } \\
\mathrm{H}_{2} \mathrm{O} \&\left[\mathrm{P}_{444} \mathrm{E}_{\mathrm{i}}^{+}\right]\left[\mathrm{DEHP}^{-}\right](\mathrm{i}=1,2,3)\end{array}$ & $\begin{array}{l}16] \\
{[17]} \\
{[18]}\end{array}$ \\
\hline Dy(III) & $\mathrm{H}_{2} \mathrm{O} \&\left[\mathrm{Hbet}^{+}\right]\left[\mathrm{Tf}_{2} \mathrm{~N}^{-}\right] \&$ bet & [16] \\
\hline $\operatorname{Er}(I I I)$ & $\mathrm{H}_{2} \mathrm{O} \&\left[\mathrm{Hbet}^{+}\right]\left[\mathrm{Tf}_{2} \mathrm{~N}^{-}\right] \&$ bet & {$[16]$} \\
\hline $\mathrm{Fe}(\mathrm{III})$ & $\mathrm{H}_{2} \mathrm{O} \&\left[\mathrm{C}_{1} \mathrm{C}_{4} \mathrm{im}^{+}\right]\left[\mathrm{FeCl}_{4}^{-}\right]$ & {$[20]$} \\
\hline $\mathrm{Ga}(\mathrm{III})$ & $\mathrm{H}_{2} \mathrm{O} \&\left[\mathrm{Hbet}^{+}\right]\left[\mathrm{Tf}_{2} \mathrm{~N}^{-}\right] \&$ bet & [16] \\
\hline $\mathrm{Ho}(\mathrm{III})$ & $\mathrm{H}_{2} \mathrm{O} \&\left[\mathrm{Hbet}^{+}\right]\left[\mathrm{Tf}_{2} \mathrm{~N}^{-}\right] \&$ bet & {$[16]$} \\
\hline $\ln (I I I)$ & $\mathrm{H}_{2} \mathrm{O} \&\left[\mathrm{Hbet}^{+}\right]\left[\mathrm{Tf}_{2} \mathrm{~N}^{-}\right] \&$ bet & {$[16]$} \\
\hline $\operatorname{Ir}(\mathrm{IV})$ & $\mathrm{H}_{2} \mathrm{O} \&\left[\mathrm{C}_{1} \mathrm{C}_{1} \mathrm{C}_{8}\right.$ pyrro $\left.{ }^{+}\right][\mathrm{Br}] \&\left[\mathrm{H}^{+}\right]\left[\mathrm{Cl}^{-}\right]$ & {$[21]$} \\
\hline $\mathrm{La}(\mathrm{III})$ & $\mathrm{H}_{2} \mathrm{O} \&\left[\mathrm{Hbet}^{+}\right]\left[\mathrm{Tf}_{2} \mathrm{~N}^{-}\right] \&$ bet & [16] \\
\hline $\mathrm{Mn}(\mathrm{II})$ & $\mathrm{H}_{2} \mathrm{O} \&\left[\mathrm{Hbet}^{+}\right]\left[\mathrm{Tf}_{2} \mathrm{~N}^{-}\right]$\&bet & [16] \\
\hline $\mathrm{Nd}(\mathrm{III})$ & $\begin{array}{l}\mathrm{H}_{2} \mathrm{O} \&\left[\mathrm{Hbet}^{+}\right]\left[\mathrm{Tf}_{2} \mathrm{~N}^{-}\right] \& \text { bet } \\
\mathrm{H}_{2} \mathrm{O} \&\left[\mathrm{chol}^{+}\right]\left[\mathrm{Tf}_{2} \mathrm{~N}^{-}\right] \&\left[\mathrm{chol}^{+}\right]\left[\mathrm{hfac}^{-}\right] \&\left[\mathrm{H}^{+}\right]\left[\mathrm{NO}_{3}^{-}\right]\end{array}$ & $\begin{array}{l}{[16,22]} \\
{[23]}\end{array}$ \\
\hline $\mathrm{Ni}(I I)$ & $\begin{array}{l}\mathrm{H}_{2} \mathrm{O} \&\left[\mathrm{Hbet}^{+}\right]\left[\mathrm{Tf}_{2} \mathrm{~N}^{-}\right] \& \text { bet } \\
\mathrm{H}_{2} \mathrm{O} \& \text { Girard- } \mathrm{IL} \\
\mathrm{H}_{2} \mathrm{O} \&\left[\mathrm{P}_{44414}^{+}\right]\left[\mathrm{Cl}^{+}\right] \&\left[\mathrm{Na}^{+}\right]\left[\mathrm{Cl}^{-}\right] \\
\mathrm{H}_{2} \mathrm{O} \&\left[\mathrm{P}_{444} \mathrm{E}_{\mathrm{i}}^{+}\right]\left[\mathrm{DEHP}^{-}\right](\mathrm{i}=1,2,3)\end{array}$ & $\begin{array}{l}{[16]} \\
{[17]} \\
{[24]} \\
{[18]}\end{array}$ \\
\hline $\mathrm{Pb}(\mathrm{II})$ & $\mathrm{H}_{2} \mathrm{O} \&\left[\mathrm{TBA}^{+}\right][\mathrm{Br}] \&\left[\mathrm{NH}_{4}^{+}\right]\left[\mathrm{SO}_{4}{ }^{2-}\right]$ & [16] \\
\hline $\mathrm{Pd}(\mathrm{II})$ & $\begin{array}{l}\mathrm{H}_{2} \mathrm{O} \&\left[\mathrm{Hbet}^{+}\right]\left[\mathrm{Tf}_{2} \mathrm{~N}^{-}\right] \&\left[\mathrm{H}^{+}\right]\left[\mathrm{NO}_{3}^{-}\right] \\
\mathrm{H}_{2} \mathrm{O} \&\left[\mathrm{chol}^{+}\right]\left[\mathrm{Tf}_{2} \mathrm{~N}^{-}\right] \&\left[\mathrm{H}^{+}\right]\left[\mathrm{NO}_{3}^{-}\right]\end{array}$ & $\begin{array}{l}{[25]} \\
{[25]}\end{array}$ \\
\hline $\operatorname{Pr}(I I I)$ & $\mathrm{H}_{2} \mathrm{O} \&\left[\mathrm{Hbet}^{+}\right]\left[\mathrm{Tf}_{2} \mathrm{~N}^{-}\right] \&$ bet & {$[16,22]$} \\
\hline $\mathrm{Pt}(\mathrm{IV})$ & $\mathrm{H}_{2} \mathrm{O} \&\left[\mathrm{C}_{1} \mathrm{C}_{8}\right.$ pyrro $]\left[\mathrm{Br}^{-}\right] \&\left[\mathrm{H}^{+}\right]\left[\mathrm{Cl}^{-}\right]$ & {$[26]$} \\
\hline $\mathrm{Rh}(\mathrm{III})$ & $\mathrm{H}_{2} \mathrm{O} \&\left[\mathrm{Hbet}^{+}\right]\left[\mathrm{Tf}_{2} \mathrm{~N}^{-}\right] \&\left[\mathrm{H}^{+}\right]\left[\mathrm{NO}_{3}^{-}\right]$ & {$[25]$} \\
\hline $\mathrm{Ru}(\mathrm{III})$ & $\begin{array}{l}\mathrm{H}_{2} \mathrm{O} \&\left[\mathrm{Hbet}^{+}\right]\left[\mathrm{Tf}_{2} \mathrm{~N}^{-}\right] \&\left[\mathrm{H}^{+}\right]\left[\mathrm{NO}_{3}^{-}\right] \\
\mathrm{H}_{2} \mathrm{O} \&\left[\mathrm{chol}^{+}\right]\left[\mathrm{Tf}_{2} \mathrm{~N}^{-}\right] \&\left[\mathrm{H}^{+}\right]\left[\mathrm{NO}_{3}^{-}\right]\end{array}$ & $\begin{array}{l}{[25]} \\
{[25]}\end{array}$ \\
\hline $\mathrm{Sc}(\mathrm{III})$ & $\begin{array}{l}\mathrm{H}_{2} \mathrm{O} \&\left[\mathrm{Hbet}^{+}\right]\left[\mathrm{Tf}_{2} \mathrm{~N}^{-}\right] \& \text { bet } \\
\mathrm{H}_{2} \mathrm{O} \&\left[\mathrm{P}_{444} \mathrm{C}_{1} \mathrm{COOH}^{+}\right]\left[\mathrm{Cl}^{-}\right] \&\left[\mathrm{Na}^{+}\right]\left[\mathrm{Cl}^{-}\right]\end{array}$ & $\begin{array}{l}{[16]} \\
{[27]}\end{array}$ \\
\hline $\mathrm{Tc}(\mathrm{VII})$ & $\begin{array}{l}\mathrm{H}_{2} \mathrm{O} \&\left[\mathrm{C}_{1} \mathrm{C}_{4} \mathrm{im}^{+}\right]\left[\mathrm{Cl}^{-}\right] \&\left[\mathrm{~K}^{+}\right]_{3}\left[\mathrm{PO}_{4}{ }^{3-}\right] \\
\mathrm{H}_{2} \mathrm{O} \&\left[\mathrm{C}_{1} \mathrm{C}_{4} \mathrm{im}^{+}\right]\left[\mathrm{Cl}^{-}\right] \&\left[\mathrm{~K}^{+}\right]_{2}\left[\mathrm{HPO}_{4}{ }^{2-}\right] \\
\mathrm{H}_{2} \mathrm{O} \&\left[\mathrm{C}_{1} \mathrm{C}_{4} \mathrm{im}^{+}\right]\left[\mathrm{Cl}^{-}\right] \&\left[\mathrm{~K}^{+}\right]_{2}\left[\mathrm{CO}_{3}{ }^{2-}\right]\end{array}$ & $\begin{array}{l}{[28]} \\
{[28]} \\
{[28]}\end{array}$ \\
\hline $\mathrm{U}(\mathrm{VI})$ & $\mathrm{H}_{2} \mathrm{O} \&\left[\mathrm{Hbet}^{+}\right]\left[\mathrm{Tf}_{2} \mathrm{~N}^{-}\right] \&\left[\mathrm{H}^{+}\right]\left[\mathrm{NO}_{3}^{-}\right]$ & [29] \\
\hline $\mathrm{Y}(\mathrm{III})$ & $\mathrm{H}_{2} \mathrm{O} \&\left[\mathrm{Hbet}^{+}\right]\left[\mathrm{Tf}_{2} \mathrm{~N}\right]$ \& bet & [16] \\
\hline $\mathrm{Zn}(\mathrm{II})$ & $\begin{array}{l}\mathrm{H}_{2} \mathrm{O} \&\left[\mathrm{Hbet}^{+}\right]\left[\mathrm{Tf}_{2} \mathrm{~N}^{-}\right] \& \text { bet } \\
\mathrm{H}_{2} \mathrm{O} \&\left[\mathrm{P}_{444} \mathrm{E}_{\mathrm{i}}^{+}\right][\mathrm{DEHP}](\mathrm{i}=1,2,3)\end{array}$ & $\begin{array}{l}{[16]} \\
{[18]}\end{array}$ \\
\hline
\end{tabular}




\subsection{IL-based ABS: definition, notations and main properties}

\subsubsection{Definitions and notations}

Although all chapters of this book deal with IL-ABS, it is very important to precisely define what this term means, in order to border the scope of this chapter. As far as ILs are concerned, we will comply with the usual definition stating that an IL is a salt of which the melting temperature, under normal pressure conditions, is equal or below $100{ }^{\circ} \mathrm{C}$. With regard to IL basic properties, the reader is referred to excellent books and reviews on this topic [30-34]. ILs' cations and anions will be noted as [Cat $\left.{ }^{+}\right]$and $\left[\mathrm{Ani}\right.$ ] , respectively, while IL will be given as [Cat $\left.{ }^{+}\right][\mathrm{Ani}]$ ], in order to highlight the ionic character of such solvents. As regards the most typical IL family, imidazolium cations will be denoted as $\left[\mathrm{C}_{n} \mathrm{C}_{m} \text { im }\right]^{+}$for $n$-alkyl-m-alkylimidazolium, while the anion $\left[\left(\mathrm{CF}_{3} \mathrm{SO}_{2}\right)_{2} \mathrm{~N}\right]^{-}$ (bis(trifluoromethylsulfonyl)imide) has been by far the most investigated. All other compounds cited in this chapter are displayed in the chemical chart provided at the end. All ILs are salts but not all salts are ILs, depending on their melting temperature. Mineral acids and salts and will be denoted according to the IL notation adopted above, e.g. $\left[\mathrm{H}^{+}\right]\left[\mathrm{Cl}^{-}\right],\left[\mathrm{Co}^{2+}\right]\left[\mathrm{Cl}^{-}\right]_{2}$ or $\left[\mathrm{Na}^{+}\right]_{2}\left[\mathrm{CO}_{3}{ }^{2-}\right]$.

By contrast, defining an ABS is somewhat more difficult. One general definition can be found in a previous review on ABS [35] as: "ABS consist of two immiscible aqueous-rich phases based on polymer-polymer, polymer-salt or salt-salt combinations. Although both solutes are water-soluble, they separate into two coexisting phases above a given concentration: one of the aqueous phases will be enriched in one of the solutes while in the other phase there is prevalence for the second polymer or salt". It thus could be easily inferred from this definition that the IL-ABS of concern in this book are simply those ABS composed of (at least) one IL, whatever the type of the other solute. However, the definition above raises more questions. First, one should define what an 'aqueous-rich phase' means as the scale on which this notion is based is not specified. Usual scales are molar, weight or volume percentages but other scales are also meaningful (see below). Considering the very large molar per liter value of water ( 55 moles per liter) as compared to other liquid compounds, such as ILs (typically in the range of 2 to 8 moles per liter), while ILs' molar weights are usually at least one order of magnitude above the $18 \mathrm{gmol}^{-1}$ of water, it is clear that the molar scale favors water, while weight percentage highlights ILs contribution. In other words, for a biphasic sample containing water and IL, either the terms water-rich or IL-rich phase might be appropriate, depending on the chosen scale. Similarly, the notions of 'enrichment' or 'prevalence' of a solute in one of the phases should be accompanied by the indication of a scale. Second, the biphasic/monophasic changes that are the signature of ABS can also occur under a temperature stimulus (thermomorphic behavior) for a fixed chemical composition, a very important point to add to the definition cited above: systems displaying either an upper critical solution temperature, UCST (above this temperature, the system is monophasic, whatever its composition) or a lower critical solution temperature, LCST (temperature below which the system is monophasic whatever its composition) exist. An alternative way to induce a change from monophasic to biphasic regimes and vice-versa, by bubbling of $\mathrm{CO}_{2}$ and $\mathrm{N}_{2}$ gases, was demonstrated by Kohno et al. [36]. However, this is in fact due to changes in the $\mathrm{pH}$ of the sample, because $\mathrm{CO}_{2}$ converts in $\left[\mathrm{CO}_{3}{ }^{2-}\right]$ anions, while $\mathrm{N}_{2}$ bubbling expels $\mathrm{CO}_{2}$. Thus, we should categorize this state change as a concentration-induced change, which is however more easy to perform and more reversible than addition of salts/dilution that always vary concentrations and volumes to large extents. 
Based on these remarks, we will therefore adopt a slightly different and somehow more restrictive definition of IL-based ABS for this chapter only. Under our understanding, IL-based ABS are systems which comply with the following five criteria:

i) They contain water;

ii) They contain at least one IL compound;

iii) They do not contain any molecular compound, apart from acidic or zwitterionic ones;

iv) They may contain other compounds in agreement with the above three criteria;

v) Within the temperature range from solidification to boiling or decomposition of the sample (under normal pressure), they present a change from monophasic to biphasic state by an increase or decrease of either temperature or concentration of at least one of their components.

Such a definition calls for some comments. First, by excluding most of the molecular compounds, we set apart systems containing polymers. This is clearly a restrictive choice of the author of this chapter as compared to the general policy of this book (in particular, see Chapter 4) but it was made in order to limit this review chapter to systems without usual neutral extracting agents, such as tributylphosphate, calixarenes or monoamides, to name a few. Second, it is important to note that this definition does not rely on notion of water-rich phase or any other type of whatsoever-rich phases. We are strongly in favor of using solely the terms upper and lower phases for describing the biphasic liquid state of ABS and IL-ABS. We will use subscripts " $u$ " and " $l$ " to denote them, while the term "initial" and its corresponding subscript "in", together with the terms "IL phase" and "aqueous phase" will refer to initial quantities and initial stock solutions, i.e. prior to mixing of the IL-ABS components. Another important point to be noted from this definition is that we consider mixtures of water and one IL to be IL-ABS, provided these present a UCST or a LCST phenomenon. This is in clear contrast with the definition given by Freire and co-workers [35] which limits ABS to a mixture of three compounds at minimum.

As regards notation of IL-ABS of concern in this chapter, this is of importance although no consensus can be found at the moment in the literature. We will list all chemicals under the chemical form they have been used for sample preparation, starting with water, each of them separated by symbol " $\&$ ", for example: $\mathrm{H}_{2} \mathrm{O} \&\left[\mathrm{H}^{+}\right]\left[\mathrm{E}^{-}\right] \&\left[\mathrm{H}^{+}\right]\left[\mathrm{X}^{-}\right] \&\left[\mathrm{~K}^{+}\right]_{3}\left[\mathrm{PO}_{4}{ }^{3-}\right] \&\left[\mathrm{C}_{1} \mathrm{C}_{4} \mathrm{im}^{+}\right]\left[\mathrm{Cl}^{-}\right]$, where $\left[\mathrm{H}^{+}\right]\left[\mathrm{E}^{-}\right]$is an acidic extractant and $\left[\mathrm{H}^{+}\right][\mathrm{X}]$ is a (mineral) acid. In case of necessity, quantities will be indicated in parenthesis after each component. Whenever possible, and in view of practical easiness (preparation protocol, for instance), we will use the mole amount of each compound, because interactions responsible for mono- to biphasic changes are clearly occurring at a molecular/ionic level. However, depending on the information available in each experimental section of the papers to be discussed, we may use molar scale or any other scale.

\subsubsection{Properties of interest of IL-ABS}

\subsubsection{Two-components systems}

IL-ABS obviously offer limited possibilities to play with as compared to systems containing more than two components, but there are nonetheless important points to be recalled in view of the review to follow in section 9.3. The easiest way to represent the thermodynamic behavior of an IL-ABS simply composed of water and one IL is through the plot of the partial miscibility curve, as schematically 
represented in Fig. 9.1a for an UCST type-system: the two-phase region is located inside the envelop and the UCST value is indicated on the y-axis. Conversely, Fig. 9.1b shows the schematic of a LCST type IL-ABS. For systems solely composed of water and one IL, a 2D plot is sufficient to fully describe their mono-/biphasic behavior, making use of the \% scale (either in mass, volume or mole). For example, the system $\mathrm{H}_{2} \mathrm{O} \&\left[\mathrm{C}_{1} \mathrm{C}_{4} \mathrm{im}^{+}\right]\left[\mathrm{BF}_{4}{ }^{-}\right]$displays a UCST equal to ca. $5^{\circ} \mathrm{C}$ while for a water amount equal to $20 \mathrm{wt} \%$, the temperature at which this system turns from mono- to biphasic, critical temperature $\left(T_{c}\right)$, is equal to $-4^{\circ} \mathrm{C}[37,38]$. Note that a clear isotopic effect is observed on UCST temperatures, as deuterated water induces an increase of the transition temperature of ca. $3.5^{\circ} \mathrm{C}$ at maximum [37]. Other examples of larger variations (up to $25^{\circ} \mathrm{C}$ ) in the turnover temperature can be found for phosphonium-based ILs and water mixtures [39]. Increases of a few degrees in UCST can also be obtained by applying pressure up to 800 bar [37].

The rather symmetrical plot displayed in Fig. 9.1a (solid line) is only obtained for $x$-axis based on mass fractions. Changing the mole fraction leads to a distorted plot with a curve now shifted to the left hand side of the diagram. This is clearly shown in the work of Rebelo et al. [37] for the $\mathrm{H}_{2} \mathrm{O}$ \& $\left[\mathrm{C}_{1} \mathrm{C}_{4} \mathrm{im}^{+}\right]\left[\mathrm{BF}_{4}^{-}\right]$system and is also schematically illustrated as a dashed line in Fig. 9.1a. This effect is the graphical translation of what has been written above concerning the scales applied to define "water-rich" phases. Other illustrations of the distortions that can be obtained by changing the scale in such plots can be found elsewhere $[40,41]$ and a very interesting discussion on the best way to plot such thermodynamic data can be found in the paper by Wagner et al [42]. In particular, it is clearly said that the mole, mass or volume fraction scales have equal validity for plotting miscibility curves. Deeper thermodynamical considerations would be in favor of the volume fraction but depending on the technique used to determine the state changes, other scales may be used, for example the refractive index or the Lorentz function of this number [42].

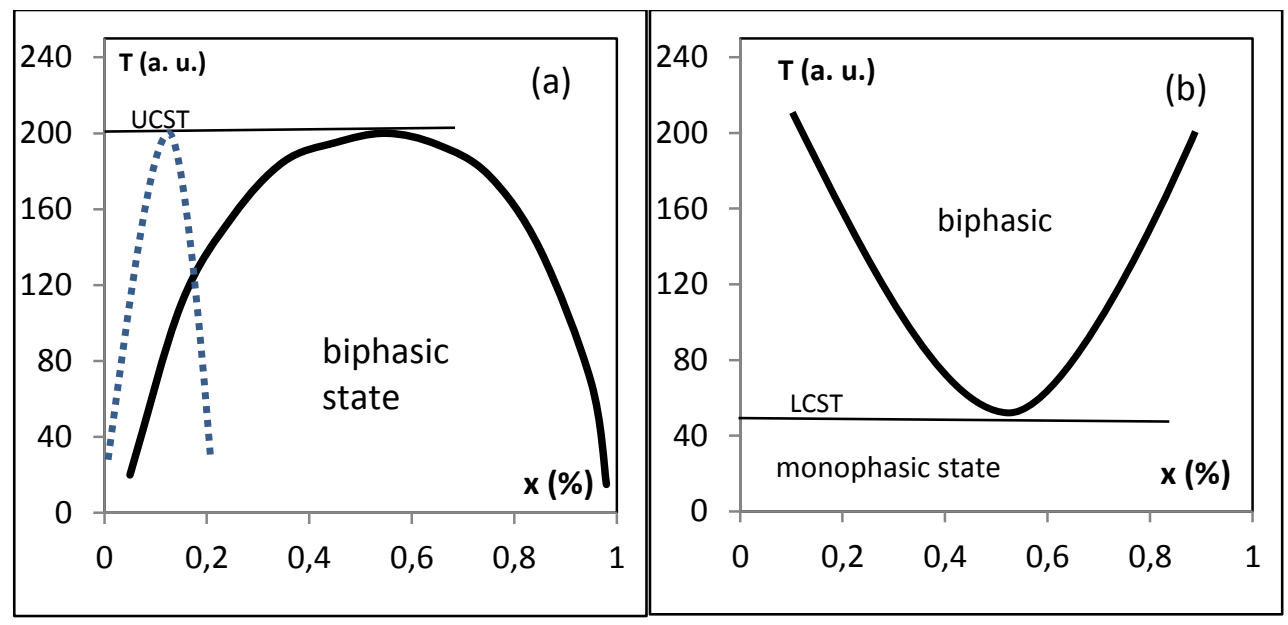

Figure 9.1 (a): Schematic plot of a miscibility curve with UCST behavior for an hypothetical system $\mathrm{H}_{2} \mathrm{O}$ \&[Cat $\left.{ }^{+}\right][$Ani $]$. Solid line: plot under the mass fraction scale. Dashed line: plot under the mole fraction scale. (b): Schematic plot of a miscibility curve with LCST behavior for an hypothetical system $\mathrm{H}_{2} \mathrm{O} \&\left[\mathrm{Cat}^{+}\right][\mathrm{Ani}]$.

According to the excellent work of Kohno and co-workers [43], who studied the transition behavior of 48 IL-water systems (ILs based on phosphonium or ammonium cations) any system of the type $\mathrm{H}_{2} \mathrm{O}$ \& [ $\left.\mathrm{Cat}^{+}\right][$Ani $]$may display one of the three following behaviors as a function of temperature $(\mathrm{T})$ : 
1) Totally miscible in the whole $\mathrm{T}$ range from 0 to $100^{\circ} \mathrm{C}$;

2) Totally immiscible within this T range;

3) Change from mono to biphasic state, either with UCST or LCST in that T range.

ILs belonging to the first category are said "real" hydrophilic ILs, while those from the second category are qualified "real" hydrophobic ILs. This way to categorize systems also calls for some comments, as it is clear that the T range $0-100^{\circ} \mathrm{C}$ has been chosen on the basis of water behavior. However, should a system $\mathrm{H}_{2} \mathrm{O}$ \& [Cat $\left.{ }^{+}\right]$[Ani'] be totally miscible whatever its composition in the range $0-100{ }^{\circ} \mathrm{C}$, this does not preclude it to experience a change from mono- to biphasic state either above $100{ }^{\circ} \mathrm{C}$ (LCST behavior) or below $0^{\circ} \mathrm{C}$ (UCST behavior). On another hand, "totally immiscible" is merely a question of detection limits and personal feeling: as ILs are composed of ions, interactions with water molecules unavoidably occur, leading to mixing, even if very limited.

For the six systems studied by these authors which display a transition from mono- to biphasic state within the range $0-100^{\circ} \mathrm{C}$, the so-called (as written by the authors) "IL-rich phase" of the biphasic state contains from 4 to $22 \mathrm{H}_{2} \mathrm{O}$ entities per IL cation-anion pair [43], so it has to be better considered as a water-rich phase under the molar percentage scale. Such systems are thus clearly IL-ABS under the definition of Freire and co-workers [35]. The system $\mathrm{H}_{2} \mathrm{O}$ \& $\left[\mathrm{chol}^{+}\right]\left[\mathrm{Tf}_{2} \mathrm{~N}^{-}\right]$, which is of interest to this chapter [44], also clearly illustrates this point. [chol $\left.{ }^{+}\right]\left[\mathrm{Tf}_{2} \mathrm{~N}^{-}\right]$melts at $\mathrm{T}=30^{\circ} \mathrm{C}$ and the system $\mathrm{H}_{2} \mathrm{O}$ \& [ $\left.\mathrm{Chol}^{+}\right]\left[\mathrm{Tf}_{2} \mathrm{~N}\right.$ ] has an UCST at $72.1{ }^{\circ} \mathrm{C}$. The authors comment that "one should use the terms hydrophobic and hydrophilic ionic liquids with caution", a statement perfectly in line with the work of Kohno and co-workers [43] discussed above. A comprehensive study of the $\mathrm{H}_{2} \mathrm{O}$ \& [chol $\left.{ }^{+}\right]\left[\mathrm{Tf}_{2} \mathrm{~N}^{-}\right]$ system in terms of the Ising theory can be found in the literature [44]. Other works also highlight the large proportion of water remaining in the lower phase of IL-ABS under their biphasic states: see [45] for ILs based on phosphonium and dicarboxylate (still $7.5 \mathrm{H}_{2} \mathrm{O}$ entities per IL pair at the transition temperature), and refer to [46] for a detailed study of the liquid structure close to the transition temperature.

\subsubsection{Three-components systems and above}

An impressive list of three-component systems together with detailed comments can be found in the review [35] by Freire and co-workers, and in other previous publications of this group $[47,48]$ so we will limit ourselves to stress a few points of decisive interest to our review chapter. In particular, the reader is referred to the work of Merchuk et al. [49], which clearly sets the experimental basis of such phenomenon although systems here studied are not IL-ABS (for kinetic aspects, see also, from the same author, Ref. [50]). The change from mono- to biphasic state by addition of a salt is also referred to "salt-in/salt-out effect" and salts are qualified kosmotropic/chaotropic, respectively. For these IL-ABS containing at least three different components, for example $\mathrm{H}_{2} \mathrm{O} \&\left[\mathrm{C}_{1} \mathrm{C}_{4} \mathrm{im}^{+}\right]\left[\mathrm{Cl}^{-}\right]$\& $\left[\mathrm{K}^{+}\right]_{3}\left[\mathrm{PO}_{4}{ }^{3-}\right]$ as studied (among others) by Gutowski and co-authors [51], a 3D (or more) plot would be necessary but authors most of the times limit themselves to $2 \mathrm{D}$ plots, displaying the mutual coexistence curve, called binodal curve, which delineates the regions of the composition diagram for which the system is either mono- or biphasic, at a fixed temperature. In such graphical representation, limits of the tie-lines give the exact compositions of the two phases, for a given global composition of the system and fixed T. Typical binodal curves and tie-lines are schematically presented in Fig. 9.2. Note that atypical binodal curves were also found in the literature [52]. 


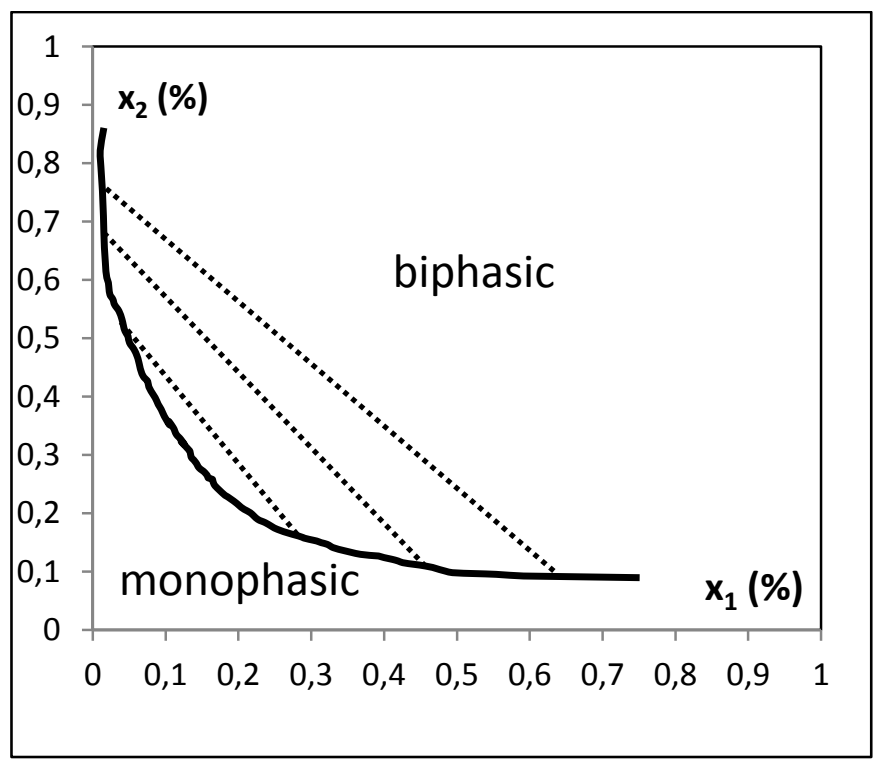

Fig. 9.2: Schematic plot of a binodal curve for an IL-ABS system with three components: water, IL and a salt. Dotted lines are tie lines.

It is of tremendous importance for the rest of this chapter to be aware that, starting from the simplest IL-ABS we defined as $\mathrm{H}_{2} \mathrm{O} \&\left[\mathrm{Cat}^{+}\right][\mathrm{Ani}$ ] , addition of any compound may impact on their thermomorphic behavior. Apart from addition of common salts such as potassium phosphate, sodium sulfate or many others as illustrated in [35], striking examples of interest to this chapter concern addition of either extracting agent (in view of enhancement of the extraction efficiency), mineral acids (in order to avoid hydrolysis/precipitation of the metallic ion) and metallic salts themselves. For example, adding betaine to $\mathrm{H}_{2} \mathrm{O} \&\left[\mathrm{Hbet}^{+}\right]\left[\mathrm{Tf}_{2} \mathrm{~N}^{-}\right]$induces a decrease of the UCST from $55.5^{\circ} \mathrm{C}$ (no betaine) to less than $40{ }^{\circ} \mathrm{C}\left(28.8 \mathrm{wt} \%\right.$ of betaine) [22]. Addition of $\left[\mathrm{H}^{+}\right]\left[\mathrm{Cl}^{-}\right]$increases the UCST ( $1 \mathrm{M}$ added, increase of $\approx 12.5^{\circ} \mathrm{C} ; 2 \mathrm{M}$ added, increase of $\approx 20^{\circ} \mathrm{C}$ ) [16, 53], while $1 \mathrm{M}\left[\mathrm{H}^{+}\right]\left[\mathrm{ClO}_{4}{ }^{-}\right]$ leads to a decrease of ca. $26^{\circ} \mathrm{C}$ [53] as compared to $\mathrm{H}_{2} \mathrm{O}$ \& $\left[\mathrm{Hbet}^{+}\right]\left[\mathrm{Tf}_{2} \mathrm{~N}^{-}\right.$] (UCST at $55^{\circ} \mathrm{C}$ ). Also of tremendous relevance in view of metal extraction is the reported decrease of UCST of ca. $20^{\circ} \mathrm{C}$ by addition of $\mathrm{Nd}(\mathrm{III})$ to $\mathrm{H}_{2} \mathrm{O}$ \& [ $\left.\mathrm{Hbet}^{+}\right]\left[\mathrm{Tf}_{2} \mathrm{~N}\right.$ ] [54], which is accompanied by an increase of the overall mutual solubilities of water and IL. Other examples of changes in the UCST or LCST values by additions of various metallic salts $\left(\left[\mathrm{Cs}^{+}\right]\left[\mathrm{Cl}^{-}\right],\left[\mathrm{Li}^{+}\right]\left[\mathrm{Cl}^{-}\right],\left[\mathrm{Na}^{+}\right]\left[\mathrm{ClO}_{4}^{-}\right],\left[\mathrm{Na}^{+}\right]\left[\mathrm{NO}_{3}^{-}\right]\right.$etc.) can be found in the literature [53]. Obviously, the comprehensive experimental study of binodal curves is impossible for systems of general formulation $\mathrm{H}_{2} \mathrm{O} \&\left[\mathrm{Cat}^{+}\right][$Ani $] \&[\mathrm{E}] \&\left[\mathrm{H}^{+}\right]\left[\mathrm{X}^{-}\right]$to be reviewed in this chapter because most extraction studies involve batch experiments with variations of the acid concentration and/or of the extractant in rather large ranges. We thus commend the attempts made to derive intuitive prediction models of such phenomena $[53,55]$. However, stricto sensu, should we limit this review to publications dealing with systems fully complying with the definition of IL-ABS we set and in particular with the fifth criterion, the number of papers to review would be dramatically limited, in part because of a lack of data on their mono/biphasic behavior. Considering these problems of classification, although we rely on our definition of IL-ABS as stated above, papers under review in this chapter have been selected because, (unless otherwise specified, see Section 9.4), a sub-part of the full system under study is known to display a change from monophasic to biphasic by either temperature or concentration variation. 
Another very important point to be recalled all times is the differences in distribution ratios of all chemical entities between the two phases. This has been detailed above for water molecules but is also true for any of the other chemical moieties of the system. As clearly demonstrated in Gutowski's work for $\mathrm{H}_{2} \mathrm{O} \&\left[\mathrm{C}_{1} \mathrm{C}_{4} \mathrm{im}^{+}\right][\mathrm{Cl}] \&\left[\mathrm{~K}^{+}\right]_{3}\left[\mathrm{PO}_{4}{ }^{3-}\right]$ [51], the distribution ratios for $\left[\mathrm{C}_{1} \mathrm{C}_{4} \mathrm{im}^{+}\right]$and $\left[\mathrm{Cl}^{-}\right]$are not perfectly equal, pointing to independent behavior of each ion. In other words, it is not because $\left[\mathrm{C}_{1} \mathrm{C}_{4} \mathrm{im}^{+}\right]$ions are introduced together with $\left.\mathrm{Cl}^{-}\right]$ions that they will perfectly distribute similarly between the two phases. This should not be overlooked. Thus, apart from the metallic entity, which is hopefully liable to massive transfer from one phase to the other, any other component of the system may be considered under the light of its extraction efficiency. This, however, necessitates the precise definition of "extraction" in such systems. Again, no real consensus exists at the moment, so we will apply a rather general, basic concept: Extraction of species $X$ means that $X$ distributes between the two phases. On a quantitative basis, most papers refer to distribution ratios of species $X$, which make reference to the concentration of that species in both the "aqueous" and the "IL" phases. On the basis of what has been discussed above, the terms upper and lower phase would be more meaningful. Furthermore, changes in the overall water content depending on T and chemical composition impose extensive experimental measurements of phase volumes and/or masses in order to apply the traditional distribution definition [22]. Therefore, in the following, whenever possible, we will better use the following expressions instead:

Extraction efficiencies:

$E_{X, u}=100 *$ amount of $X$ in the upper phase (in mole)/initial total amount of $X$ (in mole)

$E_{X, \ell}=100 *$ amount of $X$ in the lower phase (in mole)/initial total amount of $X$ (in mole)

Distribution ratios:

$D_{X, u}=$ amount of $X$ in the upper phase (in mole)/amount of $X$ in the lower phase (in mole)

$D_{X, \ell}=$ amount of $X$ in the lower phase (in mole)/amount of $X$ in the upper phase (in mole)

In the next sections, the main topic of this chapter is attempted in more detail, by first critically discussing results on metal extraction by use of "real" IL-ABS. Systems experiencing T stimulus only will be reviewed first (Sections 9.3.1 to 9.3.3), starting from very simple systems (only two components) to systems including extractant and/or acid in addition to water, IL and metallic ions. Second, systems for which concentration changes have been applied, at a fixed temperature, will be presented (Sections 9.3.4 to 9.3.6). Section 9.3.6 discusses systems for which $T$ and concentration stimulus are applied at the same time, while Section 9.3.8 summarizes results about metal stripping and recovery of ILs. Section 9.4 extends the topic to "border-line" systems.

\section{IL-ABS for metallic ions extraction}

\subsection{The ionic liquid already contains the metallic ion to be extracted}

Although there is, to the best of our knowledge, only a single paper [20] falling in this category, we found the results obtained of high interest. In particular, the number of compounds is limited to two, water and one IL, but nevertheless contains everything needed for metal extraction. In this respect, this can be considered as a case study and an emblematic system. 
Several ILs exist that contain a metallic ion, most often as the anionic part of the IL [56-58] but some (rare) examples can be found with a cationic metallic entity instead. Examples with both cationic and anionic components being metallic entities can also be found [59]. For most of these metalcontaining ILs ( $\mathrm{Mn}, \mathrm{Fe}, \mathrm{Co}, \mathrm{Gd}, \mathrm{Dy} . .$. ), magnetic properties are mostly studied and very limited knowledge is found on their thermomorphic behavior in the literature, the only example being for $\mathrm{H}_{2} \mathrm{O} \&\left[\mathrm{C}_{1} \mathrm{C}_{4} \mathrm{im}^{+}\right]\left[\mathrm{FeCl}_{4}{ }^{-}\right]$(glass transition of the IL at $\mathrm{T}=-88^{\circ} \mathrm{C}[56]$ ) which displays a LCST behavior [20, 60]. For $25 \mathrm{wt} \%$ of IL, the change from mono- to biphasic state occurs at $\mathrm{T}_{\mathrm{C}}=50{ }^{\circ} \mathrm{C}$, while at $20 \mathrm{wt} \%$ of IL, changes occurs at $T_{c}=90^{\circ} \mathrm{C}$. Below 20 wt $\%$ of IL, $\mathrm{T}$ is above $100^{\circ} \mathrm{C}$ and above $30 \mathrm{wt} \%, \mathrm{~T}_{\mathrm{c}}$ is below $10^{\circ} \mathrm{C}$ so the authors were not able to determine the complete miscibility curve [20]. Note that similar changes occur for $\mathrm{H}_{2} \mathrm{O} \&\left[\mathrm{C}_{1} \mathrm{C}_{12} \mathrm{im}^{+}\right]\left[\mathrm{FeCl}_{4}^{-}\right]$but we could not find any indication of melting point for this imidazolium compound.

Experiments have been performed by mixing $\left[\mathrm{C}_{1} \mathrm{C}_{n} \mathrm{im}^{+}\right]\left[\mathrm{FeCl}_{4}{ }^{-}\right]$and water for different chemical compositions, heating above $\mathrm{T}=70{ }^{\circ} \mathrm{C}$ to reach, whenever possible, the biphasic state. Characterization of the "oily liquid recovered" after phase separation shows that this is indeed the original IL, $\left[\mathrm{C}_{1} \mathrm{C}_{n} \mathrm{im}^{+}\right]\left[\mathrm{FeCl}_{4}^{-}\right]$. Iron distribution between the upper and lower phases has been followed by ICP-OES and evidences a rather identical presence of $\mathrm{Fe}(\mathrm{III})$ in both phases: $\mathrm{E}_{\mathrm{Fe}, \mathrm{u}}=56 \%(n=4)$ and $61 \%(n=12) . p H$ measurements indicate that $\mathrm{Fe}(\mathrm{III})$ ions undergo strong hydrolysis but no exact determination of the species found in the upper phase has been achieved. Surprisingly, the water distribution between the two phases seems to be very different from that of Fe(III), as no water IR signature could be found in the "oily" phase. Although these two systems may not come to an application, because of probable formation of hydrolyzed products, and because distribution ratios are too close to 1 , the interest here rests on the so to say ideal number of components.

Interestingly, $\left[\mathrm{C}_{1} \mathrm{C}_{n} \mathrm{im}^{+}\right]\left[\mathrm{FeCl}_{4}^{-}\right](n=4,12)$ are prepared by simply mixing $\left[\mathrm{C}_{1} \mathrm{C}_{n} \mathrm{im}^{+}\right]\left[\mathrm{Cl}^{-}\right]$and the salt $\mathrm{FeCl}_{3} .6 \mathrm{H}_{2} \mathrm{O}$ [20]. We can therefore consider that the two-component IL-ABS $\mathrm{H}_{2} \mathrm{O}$ \& $\left[\mathrm{C}_{1} \mathrm{C}_{12} \mathrm{im}^{+}\right]\left[\mathrm{FeCl}_{4}{ }^{-}\right]$ discussed above is equivalent to $\mathrm{H}_{2} \mathrm{O} \&\left[\mathrm{C}_{1} \mathrm{C}_{12} \mathrm{im}^{+}\right]\left[\mathrm{Cl}^{-}\right]$\& $\left[\mathrm{Fe}^{3+}\right]_{3}\left[\mathrm{Cl}^{-}\right]$, which is clearly an IL-ABS according to our definition but contains three individual components.

We would like also to mention another very unusual way to simulate a phase separation in such systems: as the IL under study possesses magnetic properties, the monophasic state can suffer very large concentration gradients by simply approaching a strong magnet close to the test tube. In this case, no meniscus is visible, so this does not correspond per se to a change from mono- to biphasic state, but this is a brilliant use of the IL properties [60].

\subsection{IL-ABS with betainium or choline cations and the $\left[\mathrm{Tf}_{2} \mathrm{~N}^{-}\right]$anion and other related systems}

Taken alone as a dry compound, $\left[\mathrm{Hbet}^{+}\right]\left[\mathrm{Tf}_{2} \mathrm{~N}^{-}\right]$is a solid at room temperature and melts at ca. $54^{\circ} \mathrm{C}$ $57^{\circ} \mathrm{C}[54,58]$. Thus, this compound fits within the ILs category, being also highly hygroscopic as it takes up to ca. $13 \mathrm{wt} \%$ of water at room temperature [22], is a highly viscous liquid, and, conversely, dissolves up to $15 \mathrm{wt} \%$ in water for equal volumes of water and IL put into contact at room temperature [16]. $\mathrm{H}_{2} \mathrm{O} \&\left[\mathrm{HBet}^{+}\right]\left[\mathrm{Tf}_{2} \mathrm{~N}^{-}\right]$displays a UCST at ca. $55.5^{\circ} \mathrm{C}[54,58]$. Changes in initial $\mathrm{pH}$ values of the aqueous phase also induce changes from mono to biphasic state [58], but this is not really a reversible process because neutralization of $\left[\mathrm{Li}^{+}\right]\left[\mathrm{OH}^{-}\right],\left[\mathrm{Na}^{+}\right]\left[\mathrm{OH}^{-}\right]$or $\left[\mathrm{K}^{+}\right]\left[\mathrm{OH}^{-}\right]$by any acid dilutes all the components and adds other ions to the system. Detailed partial miscibility curves, together with other physico-chemical properties of general interest (viscosity, density, thermal analysis etc.) for $\mathrm{H}_{2} \mathrm{O}$ \& $\left[\mathrm{Hbet}^{+}\right]\left[\mathrm{Tf}_{2} \mathrm{~N}^{-}\right]$can be found in [54] and [58]. 
The large water uptake and large solubilisation of $\left[\mathrm{Hbet}^{+}\right]\left[\mathrm{Tf}_{2} \mathrm{~N}^{-}\right]$in water render the terms "IL phase" and "aqueous phase", used in the papers under discussion, rather unsuitable. Although no information of densities is given, we will consider that the lower phase corresponds to the so-called "IL (rich) phase" of the papers, and, conversely, the upper phase is ascribed to the "aqueous phase".

Extraction experiments by use of $\mathrm{H}_{2} \mathrm{O}$ \& $\left[\mathrm{Hbet}^{+}\right]\left[\mathrm{Tf}_{2} \mathrm{~N}^{-}\right.$] concern $\mathrm{U}(\mathrm{VI})$ [29], $\mathrm{Pd}(\mathrm{II}), \mathrm{Rh}(\mathrm{III})$ and $\mathrm{Ru}(\mathrm{III})$ [25] or $\mathrm{Sc}$ (III) and $\mathrm{Fe}$ (III) [61]. By addition of a complexing agent, betaine, the system becomes $\mathrm{H}_{2} \mathrm{O}$ \& $\left[\mathrm{Hbet}^{+}\right]\left[\mathrm{Tf}_{2} \mathrm{~N}\right]$ \& \&et and extraction concerns $\mathrm{Cu}(\mathrm{II}), \mathrm{Y}(\mathrm{III}), \mathrm{Dy}(\mathrm{III}), \mathrm{Er}(\mathrm{III}), \mathrm{Ho}(\mathrm{III}), \mathrm{La}(\mathrm{III}), \operatorname{Pr}(\mathrm{III})$, $\mathrm{Nd}(\mathrm{III}), \mathrm{Ga}(\mathrm{III}), \operatorname{In}((\mathrm{III})$ and $\mathrm{Sc}(\mathrm{III})$ [16]. The extraction data in [22] are very similar and are limited to $\mathrm{Nd}$ (III) alone. Experiments have been performed under two very different protocols: The first one relates to traditional experimental procedures, as the aqueous and IL phases are contacted by vigorous shaking at room temperature, thus under the biphasic state $[25,29]$. Although the existence of a thermomorphic phenomenon is clearly acknowledged by the authors, they did not take advantage of it. In the second extraction protocol, the samples were heated above the UCST (at 60 ${ }^{\circ} \mathrm{C}$ ) and then cooled back to room temperature [16]. The effect of some technical aspects (the temperature at which the system is cooled below the UCST to obtain phase separation, the duration of the heating part of the protocol above UCST, centrifugation for biphasic settlement, etc.) has been studied but no comparison between the two protocols was made. As a matter of fact, comparison cannot be made by us between the two protocols based on these publications, because the metals under study are different and some of the systems investigated do not contain betaine, while others do. Finally, in a recent paper, Onghena and co-workers [61] do compare the two protocols, in view of $\mathrm{Sc}(\mathrm{III})$ and $\mathrm{Fe}$ (III) extraction, by use of $\mathrm{H}_{2} \mathrm{O} \&\left[\mathrm{Hbet}^{+}\right]\left[\mathrm{Tf}_{2} \mathrm{~N}^{-}\right]$.

The potential interest of reaching the homogeneous stage of the system and then, of inducing phase separation by decreasing the temperature below the UCST, is a question of both fundamental and industrial nature. As explained in [16], the homogeneous state may offer great advantages, because of beneficial kinetic effect onto the extraction process, but the physico-chemical reasons behind this are rather entangled. In particular, Onghena and co-workers note that stirring speeds up heat homogenization [61] and a higher temperature lowers viscosity [22]. At the same time, it is wellknown that stirring, whatever the temperature, accelerates extraction by a simple mechanical effect. Therefore, reaching the monophasic state for better mixing and finally performing phase separation at room temperature by a cooling process, or simply using vigorous stirring below UCST actually gave the same very efficient extraction of $\mathrm{SC}(\mathrm{III})$ ( $\mathrm{E} \approx 100 \%$ ). Conversely, as pinpointed in [61], heating above $55{ }^{\circ} \mathrm{C}$ has its own cost so a minute balance of pro and cons should be made in view of industrial applications, but this is out of the scope of this review. Therefore, the burst of enthusiasm about the monophasic stage advantages found in [22] is somehow dampen in a more recent publication [61]. We are convinced that performing extraction by use of the UCST limit (above and below) accelerates the kinetics of the extraction but it is our understanding that is does not enhance the thermodynamical aspect of the extraction and thus the equilibrium $E$ and $D$ values. A detailed study of these two aspects would require choosing a system for which extraction is not quantitative, in order to accurately rate the possible impacts of the experimental parameters.

In the absence of extractant or any additional compound, the extraction of Ln ions is said negligible by use of $\mathrm{H}_{2} \mathrm{O}$ \& [ $\left.\mathrm{Hbet}^{+}\right]\left[\mathrm{Tf}_{2} \mathrm{~N}^{-}\right]$[16]. No indication of means to prevent metal hydrolysis could be found in this work. In order to modify the extraction of metallic ions, two chemicals have been studied, betaine and nitric acid. The zwitterionic betaine (13 wt\%) efficiently extracts a large variety of 
elements towards the lower phase, from $\mathrm{Cu}(I I)\left(D_{\mathrm{cu}, \ell} \approx 30\right)$ to $\mathrm{Sc}(\mathrm{III})\left(\mathrm{D}_{\mathrm{sc}, \mathrm{e}} \approx 600\right)$ [16]. The lanthanides Dy, $\mathrm{Er}, \mathrm{Ho}, \mathrm{La}, \mathrm{Pr}$ and $\mathrm{Nd}$ all display $\mathrm{D}_{\mathrm{Ln}, \ell} \approx 10, \mathrm{Mn}, \mathrm{Ni}$ and $\mathrm{Zn}$ roughly distribute equally between the two phases $\left(D_{x, u} \approx 1.7\right.$ for the three elements), while Ag mainly remains in the upper phase $\left(D_{x, u} \approx\right.$ 6.7). It is interesting to note that the betaine compound has been dissolved in the aqueous phase before contact with the IL phase, which is a rather unusual procedure in traditional liquid-liquid extraction. The $\mathrm{Nd}$ distribution ratio increases as a function of betaine concentration but the authors note that betaine needs to be in very large excess as compared to the metallic ion in order to get high efficiencies (ratio of 200, $\mathrm{E}_{\mathrm{Nd}, \ell}=99 \%$ ). As already pinpointed in Section 9.2, addition of large amounts of betaine has a strong impact onto the UCST. On another hand, nitric acid also modifies significantly the extraction efficiencies (in the absence of betaine) for other metallic ions: $\mathrm{Pd}(\mathrm{II})$, $\mathrm{Rh}(\mathrm{III}), \mathrm{Ru}(\mathrm{III})$, with $\mathrm{E}_{\mathrm{x}, \mathrm{e}}$ values ranging from 100 to $95 \%, 70$ to $40 \%$ and 40 to $20 \%$ respectively, as nitric acid amount is increased [25]. Such values lead to separation factors for $\mathrm{Pd} / \mathrm{Ru}$ and $\mathrm{Pd} / \mathrm{Rh}$ in the range $50-5000$. Similar decrease was observed for $U(\mathrm{VI})$, with values $E_{\mathrm{U}, \mathrm{e}}$ from 62 to $0 \%$ as nitric acid concentration varies from $10^{-2} \mathrm{M}$ to $2 \mathrm{M}$. Therefore, for $\mathrm{U}(\mathrm{VI}), \mathrm{Pd}(\mathrm{II}) \mathrm{Rh}(\mathrm{III})$ and $\mathrm{Ru}(\mathrm{III})$, a compromise should be found between high $E_{x, e}$ values and troubles arising from hydrolysis so the authors suggest $\left[\mathrm{H}^{+}\right]_{\text {init }} \approx 0.3 \mathrm{M}[25]$. Finally, $\mathrm{E}_{\mathrm{x}, \mathrm{e}}$ values for $\mathrm{Al}(\mathrm{III})$ and $\mathrm{Na}(\mathrm{I})$ remain negligible in the whole nitric acid range investigated [29].

A mechanism has been proposed for $\mathrm{Pd}(\mathrm{II})$ extraction in the absence of betaine but presence of nitric acid $[25,29]$ and is also suggested for $\mathrm{U}(\mathrm{VI})$ extraction [29], based on an ion exchange between the upper and lower phase as:

$\mathrm{Pd}^{2+}{ }_{\mathrm{u}}+2 \mathrm{Hbet}^{+}{ }_{e} \leftrightarrows 2 \mathrm{H}_{\mathrm{u}}^{+}+\left[\mathrm{Pd}(\mathrm{bet})_{2}\right]^{2+}{ }_{e}$

Note that in the work of Sasaki et al. [25], subscripts in the chemical equilibrium proposed refer to the "aqueous" and "IL" phase so we have just changed these to the " $u$ " and " $\ell$ " subscripts we refer to. This equation is in line with the observed decrease in $D_{P d, e}$ as the initial nitric acid concentration in the system is increased, because $\mathrm{H}^{+}$increase would disfavor the formation of $\left[\mathrm{Pd}(\text { bet })_{2}\right]^{2+}$ in the lower phase, by enhancing the protonation of bet into $\mathrm{Hbet}^{+}\left(\mathrm{pK}_{\mathrm{a}}=1.83\right)$. As no measurement of the equilibrium $\mathrm{pH}$ of the upper phase has been done, this plausible explanation remains nevertheless to be firmly assessed.

In the presence of betaine and absence of nitric acid, the Binnemans group [22] independently proposed a mechanism to describe their data on $\mathrm{Nd}(\mathrm{III})$ extraction, based on the following extraction equilibrium:

$\mathrm{Nd}^{3+}{ }_{\mathrm{u}}+\mathrm{n}$ bet $_{u}+3 \mathrm{Tf}_{2} \mathrm{~N}_{\mathrm{u}}^{-}+\mathrm{x} \mathrm{H}_{2} \mathrm{O}_{\mathrm{u}} \leftrightarrows \mathrm{Nd}(\text { bet })_{n}\left(\mathrm{H}_{2} \mathrm{O}\right)_{x}\left(\mathrm{Tf}_{2} \mathrm{~N}\right)_{3 e}$

Here again, instead of species in aqueous and organic phases, we have assigned to the upper and lower phases. Based on a slope analysis of $D$ as a function of the initial betaine concentration, the authors [22] suggested the extracted species to be $\left[\mathrm{Nd}_{2}(\text { bet })_{3}\left(\mathrm{H}_{2} \mathrm{O}\right)_{x}\right]^{3+}$, with the addition that "electrical neutrality can be achieved by $\left[\mathrm{Tf}_{2} \mathrm{~N}^{-}\right]$or nitrate ions". This would require 6 negatively charged species to join the structure, as the exact charge of the complex is formally +6 , because betaine is a zwitterion, therefore an overall neutral entity ${ }^{1}$. Additionally, experimental results

\footnotetext{
${ }^{1}$ Therefore equation 9.2 is not balanced in charge.
} 
performed with $\left[\mathrm{Pr}^{3+}\right]\left[\mathrm{Br}_{3}^{-}\right]_{3},\left[\mathrm{Nd}^{3+}\right]\left[\mathrm{NO}_{3}^{-}\right]_{3}$ and $\left[\mathrm{Nd}^{3+}\right]\left[\mathrm{Cl}^{-}\right]_{3}$ all point to an ion exchange mechanism, as suggested by the authors [22], without involvement of the metal counter-anion.

It is our opinion that although the systems studied by the Japanese [25] and the Belgium [16] groups differ slightly, one single mechanism should be able to describe both data sets. In particular, we found the protonation process of betaine as acidity is increased, as discussed in [25], a reasonable assumption. Furthermore, there is no evidence of extraction of a $\mathrm{Nd}$ neutral species and the global charge of the Nd complex remains unknown at the moment. We thus propose an alternative mechanism as:

$\mathrm{Nd}^{3+}{ }_{\mathrm{u}}+\mathrm{x} \mathrm{H}_{2} \mathrm{O}_{\mathrm{u}}+3 \mathrm{Hbet}^{+} \leftrightarrows\left[\mathrm{Nd}(\text { bet })_{3}\left(\mathrm{H}_{2} \mathrm{O}\right)_{\mathrm{x}}\right]_{e}+3 \mathrm{H}_{\mathrm{u}}^{+}$

Such a mechanism is formally identical to eq. 9.2 and we think it should be valid for any of the other Ln(III) ions.

An impressive demonstration of an entire recycling process is given in [62], based on the thermomorphic system $\mathrm{H}_{2} \mathrm{O}$ \& $\left[\mathrm{Hbet}^{+}\right]\left[\mathrm{Tf}_{2} \mathrm{~N}^{-}\right]$and applied to the recycling of rare earths from $\mathrm{NdFeB}$ magnets. Real magnets were first roasted, thus turned to oxides and milled to generate particles of size in the range $6-310 \mu \mathrm{m}$. The thermomorphic system $\mathrm{H}_{2} \mathrm{O}$ \& $\left[\mathrm{Hbet}^{+}\right]\left[\mathrm{Tf}_{2} \mathrm{~N}\right.$ ] (operating temperature: $80^{\circ} \mathrm{C}$ ) easily dissolves such particles (except for a small residue, depending on the size of the particles) and by cooling the monophasic system down to room temperature, iron is mainly present in the lower phase ("IL phase"), while the rare earths (Nd, Dy) and Co are mainly present in the upper phase. Transferring iron from the lower to the upper phase can be achieved by addition ( 1 $\mathrm{M})$ of potassium salts of $\left[\mathrm{Cl}^{-}\right]$and $\left[\mathrm{C}_{2} \mathrm{O}_{4}{ }^{2-}\right]$, while $\left[\mathrm{ClO}_{4}{ }^{-}\right]$and $\left[\mathrm{NO}_{3}^{-}\right]$counter-anions only increase the affinity of $\mathrm{Nd}$, Dy and $\mathrm{Co}$ for the upper phase, without modifying the iron preference for the lower phase. Precipitation of the rare earths and cobalt with oxalic acid followed by a treatment with aqueous ammonia (which dissolves cobalt oxalate only) and calcination of the purified rare earth oxalates allowed the recovery of rare earths as very pure oxides (purity $>99.9 \mathrm{wt} \%$ ) ready for the production of new magnets. In addition of being the first demonstration of a fully integrated process from milling of used magnets until production of new pure oxides by use of IL-ABS, this study makes benefit of two properties of the $\mathrm{H}_{2} \mathrm{O} \&\left[\mathrm{Hbet}^{+}\right]\left[\mathrm{Tf}_{2} \mathrm{~N}^{-}\right]$system: its thermomorphic behavior and its ability to dissolve oxides $[58,63]$. The latter aspect avoids the classical leaching step in acidic solutions, at the expense of a possibly costly roasting procedure.

The system $\mathrm{H}_{2} \mathrm{O}$ \& $\left[\mathrm{chol}^{+}\right]\left[\mathrm{Tf}_{2} \mathrm{~N}^{-}\right]$is closely related to $\mathrm{H}_{2} \mathrm{O}$ \& $\left[\mathrm{Hbet}^{+}\right]\left[\mathrm{Tf}_{2} \mathrm{~N}^{-}\right]$. The compound [chol $\left.{ }^{+}\right]\left[\mathrm{Tf}_{2} \mathrm{~N}^{-}\right]$ is an IL (melting temperature $=30{ }^{\circ} \mathrm{C}$ ) and displays an UCST at $72{ }^{\circ} \mathrm{C}$ [44]. At room temperature and for equal volumes of water and [chol $\left.{ }^{+}\right]\left[\mathrm{Tf}_{2} \mathrm{~N}^{-}\right], 10 \mathrm{wt} \%$ of water dissolves in the lower phase while 12 wt\% of IL is found in the upper phase, a situation very similar to the $\mathrm{H}_{2} \mathrm{O}$ \& $\left[\mathrm{Hbet}^{+}\right]\left[\mathrm{Tf}_{2} \mathrm{~N}\right]$ ] systems. Other similarities can be observed, such as small changes of the UCST by addition of either $\left[\mathrm{H}^{+}\right]\left[\mathrm{NO}_{3}{ }^{-}\right]$ or extractant (increase of ca. $1{ }^{\circ} \mathrm{C}$ at low concentration of added compound, then decrease of a few degrees). Changes are also observed in the UCST value by addition of $\left[\mathrm{Nd}^{3+}\right]\left[\mathrm{NO}_{3}^{-}\right]_{3}[23]$.

The same two groups have investigated different protocols and different metallic ions. Binnemans and co-workers [23] studied the system $\mathrm{H}_{2} \mathrm{O} \&\left[\mathrm{chol}^{+}\right]\left[\mathrm{Tf}_{2} \mathrm{~N}^{-}\right] \&\left[\mathrm{chol}^{+}\right]\left[\mathrm{hfac}^{-}\right] \&\left[\mathrm{H}^{+}\right]\left[\mathrm{NO}_{3}^{-}\right] \&\left[\mathrm{Nd}^{3+}\right]_{3}\left[\mathrm{NO}_{3}{ }^{-}\right]$. The compound [ $\left.\mathrm{Chol}^{+}\right]\left[\mathrm{hfac}^{-}\right]$is an IL but here it is used as an extractant, with the additional advantage that it is less volatile than Hhfac. No experiment was performed by this group in the absence of extractant and a low nitric acid concentration was used to prevent $\mathrm{Nd}$ hydrolysis $\left(\mathrm{pH}_{\text {init }}=\right.$ 
2) [23]. Extraction was performed by heating the two phases above the UCST ( $\left.T=80^{\circ} \mathrm{C}\right)$. By contrast, Sasaki and co-workers focused on the impact of large initial nitric acid concentrations, without any extractant and extraction of $\mathrm{Pd}(\mathrm{II}), \mathrm{Ru}(\mathrm{III})$ and $\mathrm{Rh}(\mathrm{III})$ was performed under the biphasic state $(\mathrm{T}=$ $\left.25^{\circ} \mathrm{C}\right)[25]$.

As previously discussed for the $\mathrm{H}_{2} \mathrm{O} \&\left[\mathrm{Hbet}^{+}\right]\left[\mathrm{Tf}_{2} \mathrm{~N}^{-}\right]$system, $\mathrm{Nd}(\mathrm{III})$ extraction experiments demonstrate the advantage of mixing the two phases above the UCST, in terms of kinetics but identical $\mathrm{E}$ values are obtained under the two regimes (monophasic or biphasic) [23]. Transfer of $\mathrm{Nd}$ to the lower phase increases as a function of extractant, and $E_{N d, \ell}$ reaches nearly $100 \%$ above $\left[\mathrm{chol}^{+}\right]\left[\mathrm{hfac}^{-}\right]=60 \mathrm{mmol} \cdot \mathrm{kg}^{-12}$. Increase in the extractant concentration leads to a concomitant increase of the $\mathrm{pH}$ of the upper phase, which is ascribed by the authors to the protonation of the anion [hfac']. Interesting tests were performed in order to determine the maximum loading capacity of the extracted species, which is estimated at $43 \mathrm{mmol} . \mathrm{kg}^{-1}$. Above this value, a precipitate appears. On another hand, addition of $\left[\mathrm{H}^{+}\right]\left[\mathrm{NO}_{3}^{-}\right]$alone (no extractant), does not show a large impact onto $\mathrm{Pd}$ (II) and $\mathrm{Rh}$ (III) extraction in the range of initial acidities $0.3-2 \mathrm{M}$, as all $\mathrm{D}$ values remain approximatively constant and in the range $0.1-5$ [25].

Cationic exchange is proposed by the two groups $[23,25]$ to account for their data. Sasaki et al. [25] describe the extraction process according to:

$\mathrm{Pd}^{2+}{ }_{\mathrm{u}}+2 \mathrm{chol}^{+} \leftrightarrows \mathrm{Pd}^{2+}{ }_{e}+2 \mathrm{Chol}_{\mathrm{u}}^{+}$

Cationic exchange is also proposed for the Nd experiments in the presence of extractant, but no equilibrium is written, mainly because the exact stoichiometry of the extracted species cannot be determined. Some experimental evidence [23] would be in favor of four [hfac'] entities per Nd ion but the protonation of the [hfac'] introduces a bias in the slope analysis thus hampering a firm assessment. However, addition of $\left[\mathrm{chol}^{+}\right]\left[\mathrm{Cl}^{-}\right]$to the upper phase induces a decrease in $\mathrm{E}_{\mathrm{Nd}, e}$ (from 70

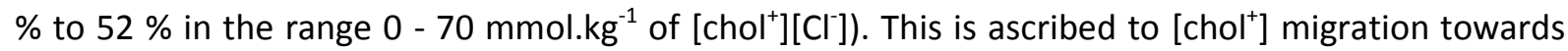
the upper phase upon $\mathrm{Nd}(\mathrm{III})$ transfer to the lower phase. Based on these experimental results and on the detailed discussion found in [23], we therefore suggest a possible extraction mechanism as:

$\mathrm{Nd}^{3+}{ }_{\mathrm{u}}+4 \mathrm{hfac}_{e}^{-}+3 \mathrm{chol}_{\ell}^{+} \leftrightarrows\left[\mathrm{Nd}(\mathrm{hfac})_{4}\right]_{e}^{-}+3 \mathrm{chol}^{+}{ }_{\mathrm{u}}$

Note that equations 9.1, 9.2, 9.4 and 9.5 are all based on cationic exchange between the metallic and the IL's cations. Cationic exchange could be further supported by analytical examination of the upper and lower phase compositions before and after metal extraction.

The cholinium cation is non-toxic and biodegradable and has been recommended in a study on antibiotic extraction as a greener approach to extraction [48]. Unfortunately, the IL compound [chol $\left.{ }^{+}\right]\left[\mathrm{hfac}^{-}\right]$is not stable upon heating and storage: 14 days of storage reduces the extraction efficiency to less than a half of the initial efficiency, a tendency is also observed if stored at ca. $6{ }^{\circ} \mathrm{C}$, and the compound is known to decompose upon heating [23]. These facts render the system rather limited for industrial applications.

Some narrow studies have been performed with the related system $\mathrm{H}_{2} \mathrm{O} \&\left[\mathrm{TMPA}^{+}\right]\left[\mathrm{Tf}_{2} \mathrm{~N}\right]$ \& $\left[\mathrm{H}^{+}\right]\left[\mathrm{NO}_{3}{ }^{-}\right]$: $\mathrm{U}(\mathrm{VI})$ is poorly extracted [29] and so are $\mathrm{Pd}(\mathrm{II}), \mathrm{Rh}(\mathrm{III})$ and $\mathrm{Ru}(\mathrm{III})$ [25].

\footnotetext{
${ }^{2}$ This concentration corresponds to the initial concentration in the single IL phase.
} 
Thermomorphic behaviors of carboxyl-functionalized ILs based either on the morpholinium cation or betaine derivatives [63], with UCST equal to $52{ }^{\circ} \mathrm{C}$ (morpholinium cation) and $55^{\circ} \mathrm{C}$ or $64{ }^{\circ} \mathrm{C}$, have been reported. Metal extraction experiments were not performed but the authors easily dissolved many metal oxides and hydroxides in such ILs. So, using these ILs for IL-ABS based metal extraction is quite a reasonable perspective.

\subsubsection{Use of ionic liquid analogues of Girard's reagents}

Blesic and co-workers performed the synthesis of a series of new ionic liquid compounds, based on the classical $\left[\mathrm{Tf}_{2} \mathrm{~N}^{-}\right]$anion and several variations upon the Girard's reagent pattern [17]. Although the Girard's reagents have melting points around $\mathrm{ca} .200^{\circ} \mathrm{C}$, and are thus not ionic liquids, the six ionic liquid versions of these salts display melting points in the range from $-55^{\circ} \mathrm{C}$ to $-36^{\circ} \mathrm{C}$. Their mixtures with water behave as USCT systems, with $\mathrm{T}_{\mathrm{c}}$ values varying from ca. $5^{\circ} \mathrm{C}$ to $95^{\circ} \mathrm{C}$ depending on the IL nature and relative proportions of water and ILs. Preliminary extraction experiments have been performed by contacting aqueous solution of either $\mathrm{Ni}(\mathrm{II}), \mathrm{Cu}(\mathrm{II}), \mathrm{Co}(\mathrm{II})$ or $\mathrm{Cr}(\mathrm{III})$ ions (initial aqueous concentration: ca. $10 \mathrm{mM}$; counter-anions: $\left[\mathrm{CH}_{3} \mathrm{CO}_{2}^{-}\right]$) with one of the Girard ILs. The authors took advantage of the USCT phenomenon and performed extraction by heating above the USCT value ( $T=$ $\left.60{ }^{\circ} \mathrm{C}\right)$ and then cooled down the samples below $\left(T=20^{\circ} \mathrm{C}\right)$ to derive the $\mathrm{D}$ values. No indication could be found in the paper on the respective volumes of the aqueous and IL phases put into contact so we thus just recall the $D$ values as published. All four metallic ions are individually extracted, quantitatively for $\mathrm{Ni}$ and $\mathrm{Cu}$ (D values at ca. 780 and $>2 \times 10^{4}$, respectively), very well for $\mathrm{Co}(\mathrm{D}=36)$ and much less for $\mathrm{Cr}(I I I)(D \approx 5)$ [17].

\subsubsection{Systems using tetrabutylammonium bromide}

Three publications (two of them by the same group) concern the system $\mathrm{H}_{2} \mathrm{O} \&\left[\mathrm{TBA}^{-}\right]\left[\mathrm{Br}^{-}\right]$\& $\left[\mathrm{NH}_{4}{ }^{+}\right]_{2}\left[\mathrm{SO}_{4}{ }^{2-}\right]$, where $\left[\mathrm{TBA}^{-}\right][\mathrm{Br}-]$ is at the upper limit of the definition we set for an IL $\left(\mathrm{T}_{\text {melt }}=100^{\circ} \mathrm{C}\right)$, and in which extractions were performed at a constant temperature by addition of one salt in order to induce the mono-/biphasic state change.

In a first step, Akama and co-workers have examined the chemical conditions leading to the ABS behavior and observed that several quaternary ammonium salts and other usual salts $\left(\left[\mathrm{Na}^{+}\right][\mathrm{Cl}]\right.$, $\left[\mathrm{Na}^{+}\right]\left[\mathrm{NO}_{3}^{-}\right]$or $\left.\left[\mathrm{NH}_{4}^{+}\right]\left[\mathrm{Cl}^{-}\right]\right)$also enable the mono-/biphasic changes but concluded that the combination of $\left[\mathrm{TBA}^{+}\right][\mathrm{Br}]$ and $\left[\mathrm{NH}_{4}^{+}\right]_{2}\left[\mathrm{SO}_{4}{ }^{2-}\right]$ is the most suitable one[64]. For example, a two-phase state is obtained at $\mathrm{T}=20^{\circ} \mathrm{C}$ for $\left[\mathrm{TBA}^{+}\right]\left[\mathrm{Br}^{-}\right]$concentration in the range $0.3-1 \mathrm{M}$ (5 mL of solution), together with $\left[\mathrm{NH}_{4}{ }^{+}\right]_{2}\left[\mathrm{SO}_{4}{ }^{2-}\right]$ from 0.1 to $1.7 \mathrm{~g}$. Starting from an initial monophasic aqueous solution volume of $5 \mathrm{~mL}$, variation of the concentrations of the two salts induce large changes in the volume of the upper phase, from $0 \mathrm{~mL}$ (monophasic state) to $4 \mathrm{~mL}$ (biphasic state). Note that such a plot (volume of upper phase as a function of global composition) is another way to display the information related to the miscibility curve, although less convenient. The authors [64] have also determined the amounts of the main ions composing the IL-ABS, namely $\left[\mathrm{TBA}^{+}\right],\left[\mathrm{NH}_{4}{ }^{+}\right],\left[\mathrm{SO}_{4}{ }^{2-}\right]$ and $\left[\mathrm{Br}^{-}\right]$, in the upper and lower phase (see Table 9.2). Their general experimental procedure indicates adjustment of the initial $\mathrm{pH}$ value at $\mathrm{pH}=3$, but unfortunately they do not comment on the equilibrium $\mathrm{pH}$ values to be observed in the upper and lower phases, although $\mathrm{H}^{+}$ions are known to distribute in a complex way in other water/IL biphasic systems [65]. Apart from uncertainties in the analytical method, this could be part of the reason explaining the observed charge balance discrepancy in the upper phase and the $10 \%$ difference in the measured and expected values for 
$\left[\mathrm{NH}_{4}^{+}\right]$amounts. As a consequence, calculated $E_{x, u}$ and $E_{x, \ell}$ values we have added in Table 9.2 should be considered with caution but these data would indicate, as previously stressed, that although $\left[\mathrm{TBA}^{+}\right]$and $\left[\mathrm{Br}{ }^{-}\right]$have been introduced in identical molar amounts, owing to their identical charges, they distribute quite differently between the two phases: the equilibrium amount (in mmol) of [TBA $\left.{ }^{+}\right]$ in the lower phase is three times less than that of [ $\left.\mathrm{Br}^{-}\right]$.

In a second step, the same group of authors have investigated the transfer from one phase to another of $\mathrm{Cd}(\mathrm{II}), \mathrm{Pb}(\mathrm{II}), \mathrm{Co}(\mathrm{II}), \mathrm{Cu}(\mathrm{II}), \mathrm{Fe}(\mathrm{III}), \mathrm{Zn}(\mathrm{II})$ in [64] and $\mathrm{Cr}(\mathrm{VI}), \mathrm{Cr}(\mathrm{III})$ (introduced as potassium salt) [19]. They have studied, in view of $\mathrm{Cd}(\mathrm{II})$ extraction, the impact of parameters such as sample volume, amount of metallic ion, and initial $\mathrm{pH}$ value of the aqueous phase in presence of interfering metallic ions ( $\mathrm{Co}(\mathrm{II}), \mathrm{Cu}(\mathrm{II}), \mathrm{Fe}(\mathrm{III})$ and $\mathrm{Zn}(\mathrm{II}))$. Note that these authors [64] use the terms "upper" and "lower" phases exactly as we do and indicate densities to be 1.05 and 1.14 at $\mathrm{T}=20^{\circ} \mathrm{C}$, respectively. They indicate that low pH values (below 0.5 ) render the IL-ABS quite unstable and their data show a strong dependence of individual extractions on the initial $\mathrm{pH}$ values $\left(\mathrm{E}_{\mathrm{Cd}, \ell}=100 \%\right.$ for $\mathrm{pH}>2$; $\mathrm{E}_{\mathrm{pb}, \ell}>$ $80 \%$ for $\mathrm{pH}$ < 4). Chemical conditions for the efficient and selective extraction of $\mathrm{Cd}(\mathrm{II})$ ( $\mathrm{Cd}$ recovery: above $90 \%$ and up to $99 \%$ ) in the presence of large amounts of $\mathrm{Zn}(\mathrm{II})$ have been determined. In case of $\mathrm{Cr}(\mathrm{VI})$ extraction, the initial $\mathrm{pH}$ value was shown to be a decisive parameter while $\mathrm{Cr}(\mathrm{III})$ was never extracted to the upper phase in significant amounts whatever the chemical conditions investigated [64]. We hypothesize that the difference in extraction ability from $\mathrm{Cr}(\mathrm{III})$ to $\mathrm{Cr}$ (IV) is mainly due to differences in charge and charge densities of the entities under study, that modify their solvation abilities. Tests have been performed in order to discriminate $\mathrm{Cr}(\mathrm{VI})$ from $\mathrm{Cr}(\mathrm{III})$ in spiked wastewater samples, and appeared to be satisfactory.

Table 9.2. Amounts (in mmol) of the various ions composing the IL-ABS $\mathrm{H}_{2} \mathrm{O} \&\left[\mathrm{TBA}^{+}\right]\left[\mathrm{Br}^{-}\right.$ ]$\&\left[\mathrm{NH}_{4}^{+}\right]_{2}\left[\mathrm{SO}_{4}^{2-}\right]$ in the upper and lower phase, as measured by Akama and co-workers [64] and as calculated from the initial amounts used. Corresponding values of $E_{x, u}$ and $E_{x, e}$ as calculated from these data (values of $\mathrm{E}$ are displayed only if above $50 \%$ ).

\begin{tabular}{|c|c|c|c|c|}
\hline & {$\left[\mathrm{TBA}^{+}\right]$} & {$[\mathrm{Br}]$} & {$\left[\mathrm{NH}_{4}{ }^{+}\right]$} & {$\left[\mathrm{SO}_{4}{ }^{2-}\right]$} \\
\hline upper phase $(\mathrm{mmol})$ & 2.5 & 1.0 & 0.9 & 0.5 \\
\hline lower phase $(\mathrm{mmol})$ & 0.6 & 1.8 & 17.0 & 7.9 \\
\hline total measured $(\mathrm{mmol})$ & 3.1 & 2.8 & 17.9 & 8.4 \\
\hline total expected (mmol) & 3.0 & 3.0 & 16.6 & 8.3 \\
\hline $\mathrm{E}_{\mathrm{X}, \mathrm{u}}(\%)$ & 83.3 & & & \\
\hline $\mathrm{E}_{\mathrm{x}, \mathrm{e}}(\%)$ & & 60.0 & 102.4 & 95.2 \\
\hline
\end{tabular}

An extraction mechanism has been proposed for the $\mathrm{Cr}(\mathrm{VI})$ extraction case [19], which is based on transfer of the neutral species $\left[\mathrm{HCrO}_{4}{ }^{-} \mathrm{TBA}^{+}\right]$from the lower to the upper phase. Although this proposal is in qualitative agreement with the slope analysis evidencing a dependency close to one $\mathrm{H}^{+}$ per $\mathrm{Cr}(\mathrm{VI})$ entity, the involvement of $\left[\mathrm{TBA}^{+}\right]$is not demonstrated yet. Two other mechanisms could be envisioned at the moment and would require further studies to be confirmed or ruled out: involvement of the chromium counter-ions, $\left[\mathrm{K}^{+}\right]$, instead of $\left[\mathrm{TBA}^{+}\right]$, or anionic exchange involving concomitant transfer (from upper to lower phase) of one $\left[\mathrm{Br}^{-}\right]$ion. 
As an opening to fascinating technological developments, we refer to the excellent work of Choi and co-workers [66], who investigated extraction of Ru (introduced as "ruthenium red", $\mathrm{Ru}\left(\mathrm{NH}_{3}\right)_{5} \mathrm{Ru}-\mathrm{O}$ $\left.\left.\mathrm{Ru}\left(\mathrm{NH}_{3}\right)_{4}-\mathrm{O}-\mathrm{Ru}\left(\mathrm{NH}_{3}\right)_{5}\right] \mathrm{Cl}_{6}\right)$ in a microfluidic system by use of the system studied by Akama and collaborators: $\mathrm{H}_{2} \mathrm{O} \&\left[\mathrm{TBA}^{+}\right][\mathrm{Br}] \&\left[\mathrm{NH}_{4}^{+}\right]_{2}\left[\mathrm{SO}_{4}{ }^{2-}\right]$. Another example of microfluidic extraction technique and results (for biological samples) can be found in [67] and a deeper presentation of the technique itself, together with insights into the theoretical aspects of microfluidic extraction with ABS is done in [68].

In the microfluidic extraction studies [66], the IL-ABS was prepared under chemical conditions leading to the biphasic state. After equilibration by vigorous shaking, the two phases were separated and fed into the two inlets of the microfluidic device. In such experimental set-up, the notions of "upper" and "lower" phases have no meaning anymore as the system is basically 1D and should be replaced by the terms "continuous" and "dispersed" phases. The phase displaying the lower density and the higher viscosity (corresponding to the upper phase in a batch experiment in classical test tubes or beakers) was used as the continuous phase. In the first part of the device, the two phases are under laminar flow and therefore do not mix. Droplets are generated by a pulsed potential difference $(150 \mathrm{~V}, 200 \mathrm{~ms})$. In the tube section where the droplets move in the bulk of the continuous phase, ruthenium red was introduced through the third inlet, as undissolved microparticles in the continuous phase [66]. This ruthenium compound has been chosen because it is highly soluble in the dispersed phase and because of its bright color, which allows an easy detection of mass transfer by the naked eye or any suitable electronic device (digital camera). In such microfluidic devices, kinetics is of tremendous importance: Ruthenium diffuses from the inlet to the main flow, then dissolves on the droplet surface and simultaneously transfers from the droplet surface to the droplet bulk until saturation. Extraction is also controlled by the number, size and guidance of the droplets, all these parameters being monitored through the potential pulse history. Consequently, droplets and/or continuous phase of controlled Ru concentrations can be obtained and this can be adjusted through time, in view of analytical needs, reaction protocols, etc. Solving the diffusion $1 \mathrm{D}$ equations allows recovering the kinetic data quite satisfactorily [66].

\subsubsection{IL-ABS with imidazolium-based ILS}

Three different works which use imidazolium-based ILs for extraction purposes of metallic ions were found in the literature $[12,13,28]$. Bridges and collaborators have studied the extraction of a rather uncommon metallic anion, $\left[\mathrm{TCO}_{4}^{-}\right]$, in view of nuclear waste processing from Hanford and Savannah River repositories, by use of the well-known IL $\left[\mathrm{C}_{1} \mathrm{C}_{4} \mathrm{im}^{+}\right]\left[\mathrm{Cl}^{-}\right]$[28]. The three systems they used, $\mathrm{H}_{2} \mathrm{O} \&\left[\mathrm{C}_{1} \mathrm{C}_{4} \mathrm{im}^{+}\right]\left[\mathrm{Cl}^{-}\right] \&\left[\mathrm{~K}^{+}\right]_{3}\left[\mathrm{PO}_{4}{ }^{3-}\right], \mathrm{H}_{2} \mathrm{O} \&\left[\mathrm{C}_{1} \mathrm{C}_{4} \mathrm{im}^{+}\right][\mathrm{Cl}]$ \& $\left[\mathrm{K}^{+}\right]_{2}\left[\mathrm{HPO}_{4}{ }^{2-}\right]$ and $\mathrm{H}_{2} \mathrm{O} \&\left[\mathrm{C}_{1} \mathrm{C}_{4} \mathrm{im}^{+}\right]\left[\mathrm{Cl}^{-}\right] \&\left[\mathrm{~K}^{+}\right]_{2}\left[\mathrm{CO}_{3}{ }^{2-}\right]$, are all well-identified IL-ABS [69]. In this study, the amount of IL was varied from 30 to $70 \mathrm{wt} \%$ in the initial aqueous phase, while the amount of the other salt was kept equal to $40 \mathrm{wt} \%$ in the other initial aqueous phase. Identical volumes of each were mixed to obtain the biphasic state. The $\mathrm{Tc}(\mathrm{VII})$ distribution ratio is readily defined as $\mathrm{D}_{\mathrm{T}, \mathrm{u}}$. For all three IL-ABS, $\mathrm{D}_{\mathrm{T} c, \mathrm{u}}$ increases as a function of the tieline length from ca. 2 to $\approx 700$ [28].

Another interesting work concerns the system $\mathrm{H}_{2} \mathrm{O} \&\left[\mathrm{C}_{1} \mathrm{C}_{6} \mathrm{im}^{+}\right]\left[\mathrm{BF}_{4}^{-}\right] \&\left[\mathrm{Na}^{+}\right]\left[\mathrm{PF}_{6}^{-}\right]$for $\mathrm{Ag}(\mathrm{I})$ extraction (introduced as its nitrate salt) [12]. $\left[\mathrm{C}_{1} \mathrm{C}_{6} \mathrm{im}^{+}\right]\left[\mathrm{BF}_{4}^{-}\right]$is also a well-known IL and $\mathrm{H}_{2} \mathrm{O} \&\left[\mathrm{C}_{1} \mathrm{C}_{6} \mathrm{im}^{+}\right]\left[\mathrm{BF}_{4}{ }^{-}\right]$ displays an UCST at $58{ }^{\circ} \mathrm{C}[40]$, so the presence of $\left[\mathrm{Na}^{+}\right]\left[\mathrm{PF}_{6}{ }^{-}\right]$is not mandatory to observe a mono/biphasic change. Although they could have used the temperature stimulus, the authors [12] used 
the $\left[\mathrm{Na}^{+}\right]\left[\mathrm{PF}_{6}^{-}\right]$salt to monitor the mono-/biphasic state changes, without any comment on that choice. Furthermore, two additional compounds are present in the studied system, as an acetate buffer, in order to control pH in dedicated experiments, and thio-Michler ketone. This last chemical was not used for extraction enhancement but as a chelating agent for UV-Vis determination of $\mathrm{Ag}$. Therefore, although we denied systems containing molecular compounds to be IL-ABS we nevertheless consider this system to be perfectly in the scope of this chapter. Finally, as far as $\left[\mathrm{PF}_{6}{ }^{-}\right]$ or $\left[\mathrm{BF}_{4}^{-}\right]$containing systems are concerned, it has been repeatedly acknowledged that such ions suffer hydrolysis when contacted with water and this point is clearly discussed in the publication presenting the phase diagrams of $\mathrm{H}_{2} \mathrm{O} \&\left[\mathrm{C}_{1} \mathrm{C}_{6} \mathrm{im}^{+}\right]\left[\mathrm{BF}_{4}{ }^{-}\right]$[40]. Apart from decomposition and $\left[\mathrm{H}^{+}\right][\mathrm{F}]$ gaseous emission, the production of $\left[\mathrm{F}^{-}\right]$also is detrimental to glassware. Furthermore, on the view point of IL-ABS, hydrolysis of the $\left[\mathrm{PF}_{6}^{-}\right]$induces large changes in relative volumes of the two phases and changes in the critical temperature. For all these reasons, the author of this chapter strongly recommends, as many others, avoiding such chemicals. Disregarding these experimental and environmental problems, the paper under review presents a rather comprehensive study of factors influencing $\mathrm{Ag}(\mathrm{I})$ extraction: $\mathrm{pH}, \mathrm{IL}-\mathrm{ABS}$ composition, addition of a third salt as $\left[\mathrm{Na}^{+}\right]\left[\mathrm{NO}_{3}^{-}\right]$, temperature and centrifugation conditions. Under the best operation conditions obtained, $\mathrm{Ag}(\mathrm{I})$ extraction reaches $100 \%$ and the system studied is very selective against a broad variety of other elements ( $\mathrm{Li}, \mathrm{Pb}, \mathrm{Al}, \mathrm{Zn}, \mathrm{Mn}, \mathrm{Hg}$, etc.). The method and the system were used for analysis of real samples (photographic wastes and river water) [12].

Recently, the related system $\mathrm{H}_{2} \mathrm{O} \&\left[\mathrm{C}_{1} \mathrm{C}_{4} \mathrm{im}^{+}\right][\mathrm{Cl}] \&\left[\mathrm{H}^{+}\right]\left[\mathrm{NO}_{3}{ }^{-}\right] \&\left[\mathrm{~K}^{+}\right]_{2}\left[\mathrm{HPO}_{4}{ }^{2-}\right]$ has also been used for silver extraction [13], but in a very different perspective: in this publication, the aim is the separation of a low amount of ${ }^{109} \mathrm{Cd}$ (carrier free) arising from the $\alpha$ irradiation of a silver target, after dissolution of the latter in nitric acid. As previously mentioned, $\mathrm{H}_{2} \mathrm{O} \&\left[\mathrm{C}_{1} \mathrm{C}_{4} \mathrm{Im}^{+}\right][\mathrm{Cl}] \&\left[\mathrm{~K}^{+}\right]_{2}\left[\mathrm{HPO}_{4}{ }^{2-}\right]$ is an IL-ABS. In view of the applications, the paper focuses on practical details needed to achieve the highest separation factor. The optimized conditions found by the authors are: $6 \mathrm{M}$ nitric acid concentration in the IL-ABS, $60 \%$ of IL $(\mathrm{w} / \mathrm{v})$, and 10 minutes settling time. With such operating conditions, a separation factor above 100 was obtained, with a recovery of ${ }^{109} \mathrm{Cd}$ in the range of $90 \%$ $(\mathrm{Ag}(\mathrm{I})$ transfers to the lower phase and $\mathrm{Cd}(\mathrm{II})$ is found in the upper phase).

\subsubsection{New systems with imidazolium, pyrrolidinium and pyridinium cations}

In a series of three successive publications, the following ten systems have been investigated for the extraction of the three different precious metallic ions, namely $\mathrm{Au}(\mathrm{III})$ [14], Pt(IV) [26] and $\operatorname{lr}(\mathrm{IV})$ [21]:

$$
\begin{aligned}
& \text { - } \mathrm{H}_{2} \mathrm{O} \&\left[\mathrm{C}_{1} \mathrm{C}_{8} \mathrm{im}^{+}\right]\left[\mathrm{Cl}^{-}\right] \&\left[\mathrm{H}^{+}\right]\left[\mathrm{Cl}^{-}\right] \&\left[\mathrm{~K}^{+}\right]\left[\mathrm{AuCl}_{4}{ }^{-}\right] \text {, } \\
& \text { - } \mathrm{H}_{2} \mathrm{O} \&\left[\mathrm{C}_{1} \mathrm{C}_{8} \mathrm{im}^{+}\right]\left[\mathrm{Br} r^{-}\right] \&\left[\mathrm{H}^{+}\right]\left[\mathrm{Br}^{-}\right] \&\left[\mathrm{~K}^{+}\right]\left[\mathrm{AuBr}_{4}{ }^{-}\right] \text {, } \\
& \text { - } \mathrm{H}_{2} \mathrm{O} \&\left[\mathrm{C}_{8} \mathrm{pyr}^{+}\right]\left[\mathrm{Br}^{-}\right] \&\left[\mathrm{H}^{+}\right]\left[\mathrm{Br}^{-}\right] \&\left[\mathrm{~K}^{+}\right]\left[\mathrm{AuBr}_{4}^{-}\right] \text {, } \\
& \text { - } \mathrm{H}_{2} \mathrm{O} \&\left[\mathrm{C}_{1} \mathrm{C}_{8} \mathrm{pyrro}^{+}\right]\left[\mathrm{Br}^{-}\right] \&\left[\mathrm{H}^{+}\right]\left[\mathrm{Br}^{-}\right] \&\left[\mathrm{~K}^{+}\right]\left[\mathrm{AuBr}_{4}{ }^{-}\right] \text {, } \\
& \text { - } \mathrm{H}_{2} \mathrm{O} \&\left[\mathrm{C}_{1} \mathrm{C}_{8} \mathrm{im}^{+}\right][\mathrm{Cl}] \&\left[\mathrm{H}^{+}\right][\mathrm{Cl}] \&\left[\mathrm{H}^{+}\right]_{2}\left[\mathrm{PtCl}_{6}^{-}\right] \text {, } \\
& -\mathrm{H}_{2} \mathrm{O} \&\left[\mathrm{C}_{1} \mathrm{C}_{8} \text { pyrro }{ }^{+}\right]\left[\mathrm{Br}^{-}\right] \&\left[\mathrm{H}^{+}\right]\left[\mathrm{Cl}^{-}\right] \&\left[\mathrm{H}^{+}\right]_{2}\left[\mathrm{PtCl}_{6}^{-}\right], \\
& \text {- } \mathrm{H}_{2} \mathrm{O} \&\left[\mathrm{C}_{12}\left(\mathrm{C}_{1} \mathrm{im}\right)_{2}{ }^{2+}\right] 2\left[\mathrm{Br}^{-}\right] \&\left[\mathrm{H}^{+}\right]\left[\mathrm{Cl}^{-}\right] \&\left[\mathrm{H}^{+}\right]_{2}\left[\mathrm{PtCl}_{6}{ }^{-}\right] \text {, }
\end{aligned}
$$




$$
\begin{aligned}
& -\mathrm{H}_{2} \mathrm{O} \&\left[\mathrm{C}_{1} \mathrm{C}_{8} \mathrm{im}^{+}\right][\mathrm{Br}] \&\left[\mathrm{H}^{+}\right]\left[\mathrm{Cl}^{-}\right] \&\left[\mathrm{~K}^{+}\right]_{2}\left[\mathrm{IrCl}_{6}{ }^{2-}\right], \\
& -\mathrm{H}_{2} \mathrm{O} \&\left[\mathrm{C}_{1} \mathrm{C}_{1} \mathrm{C}_{8} \mathrm{pyrid}^{+}\right]\left[\mathrm{Br}{ }^{-}\right] \&\left[\mathrm{H}^{+}\right]\left[\mathrm{Cl}{ }^{-}\right] \&\left[\mathrm{~K}^{+}\right]_{2}\left[\mathrm{IrCl}_{6}{ }^{2-}\right], \\
& -\mathrm{H}_{2} \mathrm{O} \&\left[\mathrm{C}_{1} \mathrm{C}_{1} \mathrm{C}_{8} \mathrm{im}^{+}\right]\left[\mathrm{Br}{ }^{-}\right] \&\left[\mathrm{H}^{+}\right]\left[\mathrm{Cl}^{-}\right] \&\left[\mathrm{~K}^{+}\right]_{2}\left[\mathrm{IrCl}_{6}{ }^{2-}\right]
\end{aligned}
$$

For all these systems, addition of the IL compound to the aqueous phase containing a mineral acid and the metallic ion leads to a biphasic system, either liquid-liquid or solid-liquid: compounds obtained with $\left[\mathrm{C}_{1} \mathrm{C}_{1} \mathrm{C}_{8}\right.$ pyrro $\left.{ }^{+}\right]$and $\mathrm{Au}(\mathrm{III}),\left[\mathrm{C}_{1} \mathrm{C}_{1} \mathrm{C}_{8} \mathrm{im}^{+}\right]$or $\left[\mathrm{C}_{12}\left(\mathrm{C}_{1} \mathrm{im}\right)_{2}{ }^{2+}\right]$ and $\mathrm{Pt}(\mathrm{IV}),\left[\mathrm{C}_{1} \mathrm{C}_{1} \mathrm{C}_{8} \mathrm{im}^{+}\right]$or $\left[\mathrm{C}_{1} \mathrm{C}_{1} \mathrm{C}_{8} \mathrm{im}^{+}\right]$and $\operatorname{Ir}(\mathrm{IV})$ are solids, some of them sticking very well to the walls of the polyethylene test tubes, while all other compounds are liquids (with higher densities than the other phase, therefore becoming the lower phase) under the chemical conditions used. However, as noted by us [14], liquid lower phases could be the result of very hygroscopic solids (that we may also call water-rich phase). Note that none of the water content has been analyzed for any of the obtained compound.

As far as we know from the literature, none of these systems had been shown to present a change from mono- to biphasic state before these three publications $[14,21,26]$. Although no reference has been made in the above mentioned publications to ABS as such, all these systems correspond to ILABS under our definition. Interestingly, these systems are one of the very rare examples of IL-ABS containing large amounts ( $1 \mathrm{M}$ or above) of a mineral acid as one of the key constituents, while most of the known IL-ABS deal with alkaline, neutral or slightly acidic mixtures [70]. These acidic conditions are clearly an advantage in view of metal extraction, in order to avoid hydrolysis and/or precipitation.

Extraction of the three metals towards the lower phase strongly depends on the global mineral acid concentration and on the exact nature of the IL compound but for all three metals, chemical conditions leading to very high extraction efficiencies could be found $\left(E_{x, \ell}>90 \%\right)$. The authors [14] note that these experiments correspond to a metathesis procedure leading to the formation of an insoluble IL (i.e. insoluble in an aqueous acidic phase), which is actually a very classical way to synthesize ILs and thus they proposed a mechanism as:

$$
\begin{array}{ll}
\mathrm{Cat}^{+}+\mathrm{MX}_{4}^{-} \leftrightarrows \text { CatMX }_{\mathrm{p}} & (\mathrm{M}=\mathrm{Au}) \\
2 \mathrm{Cat}^{+}+\mathrm{MX}_{6}^{2-} \leftrightarrows \mathrm{Cat}_{2} \mathrm{MX}_{\mathrm{p}} & (\mathrm{M}=\mathrm{Pt}, \mathrm{Ir})
\end{array}
$$

where $\mathrm{X}=\mathrm{Cl}$ or $\mathrm{Br}$, accordingly. Characterization of the collected fractions (lower phases) by NMR or IR (Pt and Ir cases, collected fractions for Au were too small) confirmed the presence of the IL cation and UV-vis spectra confirmed the presence of the halide metallic entity. Equations 9.6 and 9.7 are ascribable to a precipitation mechanism and the authors used this term all along, whatever the exact state (liquid or solid) of the lower phase obtained ${ }^{3}$. The authors [14] consequently developed a simple mathematical treatment, based on the classical definition of a solubility product to determine the $K_{s}$ values of each compound. Although this formalism well describes the results obtained, $a$ model based on anionic exchange could also be considered for the liquid-liquid biphasic systems as (adaptation to the Ir and Pt cases is straightforward):

\footnotetext{
${ }^{3}$ This corresponds to the counter-intuitive (but stimulating) notion of precipitation of a liquid, that could possibly be lying as an upper phase. This observation can also be found in the recent paper [53] Dupont D, Depuydt D, Binnemans K, (2015) Overview of the effect of salts on biphasic ionic liquid/water solvent extraction systems: anion exchange, mutual solubility and thermomorphic properties. J. Phys. Chem. B 119:6747-6757.
} 
In the case of the liquid lower phases we consider both models to be formally identical.

Such experiments lead to a new metal-containing ILs quite similar to the $\left[\mathrm{C}_{1} \mathrm{C}_{4} \mathrm{im}^{+}\right]\left[\mathrm{FeCl}_{4}{ }^{-}\right]$which has been presented in Section 9.3.1 above. They are also very similar to the synthesis of the liquid compound $\left[\mathrm{C}_{1} \mathrm{C}_{8} \mathrm{im}^{+}\right]_{2}\left[\mathrm{Ce}\left(\mathrm{NO}_{3}\right)_{6}{ }^{2-}\right]$ by adding $\left[\mathrm{C}_{1} \mathrm{C}_{8} \mathrm{im}^{+}\right][\mathrm{Cl}]$ to a strongly acidic aqueous solution $\left(\left[\mathrm{H}^{+}\right]\left[\mathrm{NO}_{3}^{-}\right]>7 \mathrm{M}\right)$ in which $\left[\mathrm{Ce}^{4+}\right]\left[\mathrm{NO}_{3}^{-}\right]_{4}$ has been dissolved: Upon addition of the IL, a red viscous liquid forms at the bottom [15] and the authors propose an anionic exchange similar to eq. 9.8 to be the rationale for that reaction. Another work in relation with this is the synthesis of imidazolium ILs bearing aminodiacetic moieties as di-tert-butyl ester [71]. One of them, put in contact with a water solution containing $\mathrm{Cu}(\mathrm{II})$ leads to a cupper complex forming a separate different phase.

\subsubsection{Use of phosphonium-based ILs}

This section presents extraction data for an IL-ABS system for which both T and salt concentration are used in conjunction to induce phase changes. Phosphonium-based ILs are relatively new comers in the field of metallic ion extraction [72], as compared to imidazolium-based ILs. Under the commercial generic names of Cyphos (Cytec), they are in particular available as chloride, bromide and dicyanamide salts, thus being fluorine-free ILs. Addition of $\left[\mathrm{Na}^{+}\right]\left[\mathrm{Cl}^{-}\right]$, a cheap and efficient salting-out agent, induces a thermomorphic behavior for $\mathrm{H}_{2} \mathrm{O} \&\left[\mathrm{P}_{44414}{ }^{+}\right]\left[\mathrm{Cl}^{-}\right]$. The turnover temperature can vary from $40^{\circ} \mathrm{C}$ down to $0^{\circ} \mathrm{C}$ as the sodium chloride amount is increased from 2 to $11 \mathrm{wt} \%$ [24]. Other examples of mono/biphasic changes upon composition of the phosphonium-IL /water mixtures, for non-commercial compounds, can be found in [73].

To the best of our knowledge, extraction of metallic ions using such phosphonium-based ILs in IL-ABS was performed only by the Binnemans group so far $[18,61]$. Such experiments concern $\mathrm{Co}, \mathrm{Ni}, \mathrm{Cu}$ and $\mathrm{Zn}$, on the one hand, and $\mathrm{Sc}$ on another hand. Using the system $\mathrm{H}_{2} \mathrm{O} \&\left[\mathrm{P}_{44414^{+}}{ }^{+}\right]\left[\mathrm{Cl}^{-}\right](40$ $w t \%) \&\left[\mathrm{Na}^{+}\right]\left[\mathrm{Cl}^{-}\right]$(5 to $\left.11 \mathrm{wt} \%\right), \mathrm{Ni}(\mathrm{II})$ was efficiently separated from $\mathrm{Co}(\mathrm{II})\left(1 \mathrm{~g} \cdot \mathrm{kg}^{-1}\right.$ each), the latter being extracted to the "IL-rich phase" (i.e. most probably the upper phase of the biphasic system, as phosphonium-ILs are most of the time less dense than aqueous solutions). In this case, the system was cooled below the LCST temperature (monophasic state) and then heated up (biphasic state) but no information on the two operating temperatures could be found. A separation factor of ca. 500 was obtained. This is an interesting example of extraction which benefits both from the addition of a salting-out agent and of the thermal stimulus in order to obtain and drive the biphasic/monophasic changes. This is useful for complete and fast mixing, first and, second, phase separation. By contrast, systems as $\mathrm{H}_{2} \mathrm{O} \&\left[\mathrm{P}_{444} \mathrm{E}_{i}^{+}\right]\left[D E H P^{-}\right] \quad(i=1,2,3)$ do not require salt addition to display tractable mono/biphasic changes upon temperature $\left(T_{c}\right.$ from $60^{\circ} \mathrm{C}$ to $20^{\circ} \mathrm{C}$ depending on the exact IL nature, LCST type behavior) but do not allow for neither a $\mathrm{Co} / \mathrm{Ni}$ efficient separation, nor for separation of $\mathrm{Cu}(\mathrm{II})$ and $\mathrm{Zn}(\mathrm{II})$, all four elements being extracted with $\mathrm{D}$ values in the range $4-25$ [18]. Another drawback of these systems is, as stressed above, a large effect of metal concentration onto the turnover temperature, which can be reduced by ca. $20^{\circ} \mathrm{C}$. As discussed by the authors, this effect is interesting on the view point of energy consumption and practical easiness but limits the metal loading to $8000 \mathrm{ppm}$, in order to prevent a temperature change below $0^{\circ} \mathrm{C}$.

The system $\mathrm{H}_{2} \mathrm{O}(500 \mathrm{mg}) \&\left[\mathrm{P}_{444} \mathrm{C}_{1} \mathrm{COOH}^{+}\right]\left[\mathrm{Cl}^{-}\right](500 \mathrm{mg}) \&\left[\mathrm{Na}^{+}\right]\left[\mathrm{Cl}^{-}\right](8 \mathrm{wt} \%)$ was also used for studying $\mathrm{Sc}(\mathrm{III})$ extraction (introduced as its chloride salt, at concentration equal to $5 \mathrm{mmol} . \mathrm{kg}^{-1}$ ) [27]. Again, 
addition of the metallic ion of interest impacts the binodal curve. Scandium is efficiently extracted from aqueous phases and the effect of contact time and $\mathrm{pH}$ (in the range $0-3.3$, in order to avoid Sc hydrolysis) was examined. However, increasing the initial amount of Sc above ca. $10 \mathrm{mmol} . \mathrm{kg}^{-1}$ decreases the extraction efficiency, due to saturation of the receiving phase. Insights into the extraction mechanism are given, substantiated by NMR and IR measurements. Note that in an IL phase, the exact state, either associated or not, of any charged species is difficult to ascertain [74] and the same fundamental question arises in "IL-rich phases". We thus suggest that the formation of the neutral species $\left.\left[\mathrm{P}_{444} \mathrm{C}_{1} \mathrm{COO}\right)_{3} \mathrm{SC}\right] \mathrm{Cl}_{3}$, as proposed by the authors [27], is as valid as our suggestion of the formation of $\left.\left[\mathrm{P}_{444} \mathrm{C}_{1} \mathrm{COO}\right)_{3} \mathrm{Sc}\right]^{3+}+\left[\mathrm{Cl}^{-}\right]_{3}$ is, because the differences between the two proposals are merely a question of considering or not a coordination sphere. Stripping experiments have been successfully performed, by use of the classical route of oxalic acid addition, inducing oxalate precipitates.

\subsubsection{Stripping and recycling}

The final aim of any extraction process is to concentrate the metal under any suitable form (oxide, salt, neat metal, etc.) in a monophasic aqueous phase while the IL is recovered in view of recycling. Starting from the individual phases of IL-ABS, which both contain large amounts of water and IL, this can be named "metal recovery" or "metal stripping", in reference to traditional extraction process, or "IL recovery". The use of IL-ABS is clearly a disadvantage, because, as pinpointed by the Binnemans' group [22], IL-ABS are based on the high solubility of IL into aqueous phases and vice-versa. Although, in a successful (i.e. efficient) extraction, the metal has been massively transferred from one phase to the other, by contrast, the IL is distributed between two phases, which implies multiple stripping procedures for its recovery. The recovery of the extractant is an additional problem to cope with, especially considering the large changes in composition of the IL-ABS as a function of all its components, as previously discussed. Furthermore, all other metallic ions present in the starting aqueous phase may interfere with the recovery procedures. These problems are not too often tackled in fundamental studies and we commend the work and efforts of the Binnemans group [27, $61,75]$ on these points. In the following, we simply gather some results on the general problem of metal, extractant and IL as found in the papers discussed above.

For any recovery procedure requiring acids, the use of $\left[\mathrm{H}^{+}\right]\left[\mathrm{Tf}_{2} \mathrm{~N}^{-}\right]$is limited by the unusual thermomorphic behavior of $\mathrm{H}_{2} \mathrm{O} \&\left[\mathrm{H}^{+}\right]\left[\mathrm{Tf}_{2} \mathrm{~N}\right]$, as observed [76] and discussed [77] in previous papers. As for back-extraction of metallic ions, this subject is scrutinized in many papers. Various backtransfer protocols have been tested, depending on metal and samples. Contacting the IL-rich phase with acidic aqueous solution may be efficient [17], but precipitation using oxalic acid is also very common $[18,27,61,62]$. More specific means, as reduction from $\mathrm{Tc}(\mathrm{VII})$ to $\mathrm{Tc}(\mathrm{V})$ by addition of $\left[\mathrm{Sn}^{2+}\right]\left[\mathrm{Cl}_{2}\right]_{2}$ have also been tested in the literature but appear to be far from perfect [28]. Most of the time, stripping procedures lead to further losses of the IL components, in a way rather difficult to predict, as this depends, among other parameters, on the nature and amount of acid, but also on the metal concentration, a problem discussed in the studies with the $\mathrm{H}_{2} \mathrm{O}$ \& [ $\left.\mathrm{Hbet}^{+}\right]\left[\mathrm{Tf}_{2} \mathrm{~N}^{-}\right]$system [23]. In some other cases, precipitation of the metallic salt regenerates the IL compound at the same time $[27,62]$. 
In the case an extracting agent has been used, closing the cycle often requests to change its protonation state, which has been modified during the course of the IL-ABS extraction. Washing with water is often used for that purpose [18].

Finally, in view of recovering ionic liquids from aqueous samples, the use of $\left[\mathrm{Al}^{3+}\right]_{2}\left[\mathrm{SO}_{4}{ }^{2-}\right]_{3}$ and $\left[\mathrm{Al}^{3+}\right]\left[\mathrm{K}^{+}\right]\left[\mathrm{SO}_{4}{ }^{2-}\right]_{2}$ has been successfully tested [78]. The system $\mathrm{H}_{2} \mathrm{O} \&\left[\mathrm{Cat}^{+}\right][\mathrm{Ani}]$ \& $\left[\mathrm{Al}^{3+}\right]_{2}\left[\mathrm{SO}_{4}{ }^{2-}\right]_{3}$ (or $\left.\mathrm{Al}^{3+}\right]\left[\mathrm{K}^{+}\right]\left[\mathrm{SO}_{4}{ }^{2-}\right]_{2}$ ) is in fact an IL-ABS which does not extract aluminum but generates a biphasic state upon aluminum salt addition, thus cleaning the aqueous phase from its undesired IL content. The ILs under investigation belong to the imidazolium, phosphonium and pyridinium families. Percentages of IL recovery were all above $90 \%$ [78]. This is an unexpected use of an IL-ABS which is not efficient for Al recovery but is still of interest to a closed cycle.

\subsection{Could (should) all extraction systems with $\mathrm{H}_{2} \mathrm{O}$ and ILs be considered as IL-ABS?}

This question may appear rather provocative, of course, but it is our opinion that there is a continuous link between IL-ABS as reviewed above and any extraction system composed of (at least) water and one IL, plus a metallic entity to be extracted. In order to better sustain this paradigm, we will first present in the two sub-sections to follow, typical examples of what we consider as two missing links between "real" IL-ABS and any other systems of the type $\mathrm{H}_{2} \mathrm{O}$ \& [Cat ${ }^{+}$][Ani']. Then, in the third sub-section, few general comments are provided.

\subsubsection{Extraction with $\left[\mathrm{C}_{1} \mathrm{C}_{n} \mathrm{im}^{+}\right]\left[\mathrm{Tf}_{2} \mathrm{~N}^{-}\right]$or $\left[\mathrm{C}_{1} \mathrm{C}_{4} \mathrm{im}^{+}\right]\left[\mathrm{PF}_{6}^{-}\right]$}

Systems of the type $\mathrm{H}_{2} \mathrm{O} \&\left[\mathrm{C}_{1} \mathrm{C}_{n} \mathrm{im}^{+}\right]\left[\mathrm{Tf}_{2} \mathrm{~N}^{-}\right](n=2,3,4,5,6,7,8)$ also display an UCST behavior [79], but, owing to the physico-chemical properties of these ILs, the miscibility curve could not be obtained in the full range of IL contents: In the range of IL mole fraction $0.001-0.7$, all systems are biphasic from ca. $17{ }^{\circ} \mathrm{C}$ up to $47^{\circ} \mathrm{C}$, which, most of the time, corresponds to a workable $\mathrm{T}$ range for laboratory scale experiments. Moreover, as the measured two parts of the miscibility curve are very steep, the biphasic state could be evidenced either for very low $\left(<10^{-3}\right.$ mole fraction) or rather high (> 0.7 mole fraction) amounts of ILs in this accessible $T$ range. To fix ideas, for the rather common $\left[\mathrm{C}_{1} \mathrm{C}_{4} \mathrm{im}^{+}\right]\left[\mathrm{Tf}_{2} \mathrm{~N}^{-}\right] \mathrm{IL}$, at $\mathrm{T}=25^{\circ} \mathrm{C}$, contacting $5 \mathrm{~mL}$ of pure water and that IL leads to a biphasic state for IL volumes from ca. $70 \mu \mathrm{L}$ to $219 \mathrm{~mL}$. Rather similar values are obtained for the other ILs ( $n=2$ to 8). Owing to the price of ILs and to the difficulty in handling very low volumes, most workable extraction studies based on $\mathrm{H}_{2} \mathrm{O} \&\left[\mathrm{C}_{1} \mathrm{C}_{4} \mathrm{im}^{+}\right]\left[\mathrm{Tf}_{2} \mathrm{~N}^{-}\right]$thus correspond to a very stable biphasic system composed of equal volumes of water and IL. Note that in the publications of concern, acids (nitric, hydrochloric etc.) and/or acidic extractants could be added to the system to avoid metal hydrolysis and enhance extraction efficiencies, respectively. Those additional compounds may modify the borders of the miscibility curve, as could also large amounts of metal added do, as already stressed in Section 9.2, but as a matter of fact monophasic states have not been observed by any of the authors, so we may conclude that acids, extractants and metallic ions do not dramatically reduce the biphasic envelop of the miscibility curve. Consequently, as far as we know from a broad literature survey (for reviews in the field, see $[3,4])$, none of the numerous works performed with the general extraction systems $\mathrm{H}_{2} \mathrm{O} \& \mathrm{E} \&\left[\mathrm{C}_{1} \mathrm{C}_{n} \mathrm{im}^{+}\right]\left[\mathrm{Tf}_{2} \mathrm{~N}^{-}\right] \&\left[\mathrm{H}^{+}\right]\left[\mathrm{X}^{-}\right]$for metal extraction mention the existence of an UCST behavior, starting from our own publications in the field [80-82]. In our defense, it is most probable that very 
high temperatures would be needed to obtain a monophasic system, which would limit a lot the advantages of that protocol.

Similar very broad biphasic state is obtained for the system $\mathrm{H}_{2} \mathrm{O} \&\left[\mathrm{C}_{1} \mathrm{C}_{4} \mathrm{im}^{+}\right]\left[\mathrm{PF}_{6}{ }^{-}\right]$[41], in the $\mathrm{T}$ range $\approx$ $10{ }^{\circ} \mathrm{C}-87^{\circ} \mathrm{C}$ so the same conclusions as above are derived: apart from a few noticeable exceptions (see below), none of the publications dealing with $\mathrm{H}_{2} \mathrm{O} \&\left[\mathrm{C}_{1} \mathrm{C}_{4} \mathrm{im}^{+}\right]\left[\mathrm{PF}_{6}{ }^{-}\right]$mention the UCST behavior of the system they are working on. However, considering the instability of $\left[\mathrm{PF}_{6}^{-}\right]$towards hydrolysis as already discussed, again, we would not recommend this system for metal extraction. Exceptions concern only systems in which the amount of $\left[\mathrm{C}_{1} \mathrm{C}_{4} \mathrm{im}^{+}\right]\left[\mathrm{PF}_{6}{ }^{-}\right]$is very low, owing to cost of the compound. Keywords of these publications refer to liquid phase microextraction [83] or micro volume [84]. These two works present extraction of $\mathrm{Pb}(\mathrm{II})$ and $\mathrm{Ni}(\mathrm{II})[83,84]$. In these experiments, volumes are in the range of less than $10 \mu \mathrm{L}$ for IL versus $3 \mathrm{~mL}$ of aqueous phase [83] or $500 \mu \mathrm{L}$ of IL contacted with $10 \mathrm{~mL}$ of aqueous solution [84].

\subsubsection{Imidazolium nonafluorobutanesulfonate ABS}

Only two papers $[85,86]$ take advantage of $\left[\mathrm{H}_{2} \mathrm{O}\right] \&\left[\mathrm{C}_{1} \mathrm{C}_{n} \mathrm{im}^{+}\right]\left[\mathrm{NfO}^{-}\right](n=4,5,6)$ mixtures for metal extraction ( $\mathrm{La}, \mathrm{Eu}$, and $\mathrm{Li}, \mathrm{Na}, \mathrm{Cs}, \mathrm{Ca}$ and $\mathrm{Sr}$ ). In one case, only nitric acid was added [86], while a mixture of $\left[\mathrm{Na}^{+}\right]\left[\mathrm{ClO}_{4}^{-}\right]$and $\left[\mathrm{H}^{+}\right]\left[\mathrm{ClO}_{4}^{-}\right]$, together with the acidic extractant $\left[\mathrm{H}^{+}\right]\left[\mathrm{TTA}^{-}\right]$is used in the other case. To the best of our knowledge, these systems have not proved yet to experience changes from monophasic to biphasic state as a function of T or concentration (fifth criterion in Section 9.2). Therefore, strictly speaking, they cannot be considered as real IL-ABS under our definition but we consider them to be emblematic of the general ideas and results when using IL-ABS. In fact, it is our opinion that they are a perfect illustration of the gradation evoked in the introduction of Section 9.4.

Jensen and co-workers [85] observed large changes in volumes when equilibrating neat, dry $\left[\mathrm{C}_{1} \mathrm{C}_{4} \mathrm{im}^{+}\right]\left[\mathrm{NfO}^{-}\right]$and aqueous (perchloric/perchlorate) phases, giving birth to the system $\mathrm{H}_{2} \mathrm{O} \&\left[\mathrm{C}_{1} \mathrm{C}_{4} \mathrm{im}^{+}\right]\left[\mathrm{NfO}^{-}\right] \&\left[\mathrm{H}^{+}\right]\left[\mathrm{ClO}_{4}^{-}\right] \&\left[\mathrm{Na}^{+}\right]\left[\mathrm{ClO}_{4}^{-}\right]$. As no indication of phase inversion could be found in both papers, we will assume that the lower phase corresponds to what is called an "IL phase " in [85] and [86]. An expansion of ca. $40 \%$ of the volume of the formerly dry IL phase is indicated, accompanied by a substantial decrease of the volume of the other phase [85] but it has to be noted that the starting volumes of both phases are not specified in this paper. However, based on standard procedures, we may assume the preparation protocol to be based on identical volumes of IL and aqueous phase before contact. At equilibrium, the authors note that "the water content of neat IL phase is equal to $20.7 \mathrm{wt} \%$ (10.9 mole $\mathrm{H}_{2} \mathrm{O}$ per liter)", which corresponds to ca. "6.4 $\mathrm{H}_{2} \mathrm{O}$ molecules per $\mathrm{C}_{1} \mathrm{C}_{4} \mathrm{im}^{+} \mathrm{NfO}^{-}$pair" [85]. It is clear that the so-called neat IL phase obtained by this protocol (with or without $\left[\mathrm{H}^{+}\right]\left[\mathrm{TTA}^{-}\right]$) should be better considered as an aqueous phase containing large amounts of $\left[\mathrm{C}_{1} \mathrm{C}_{4} \mathrm{im}^{+}\right]$and $\left[\mathrm{NfO}^{-}\right]$. This perfectly corresponds to the notion of "two immiscible aqueous-rich phases" of Freire and co-workers [35] and is also in line with the results of Kohno et al. [43] detailed in Section 9.2. Furthermore, addition of $0.5 \mathrm{M}$ of $\left[\mathrm{H}^{+}\right]\left[\mathrm{TTA}^{-}\right]$modifies significantly the water amount in the lower phase, with a decrease to $14.2 \mathrm{w} \%$, a phenomenon which resembles previous observations on the impact of $\mathrm{Hbet}$ and $\left[\mathrm{H}^{+}\right]\left[\mathrm{Cl}^{-}\right][16,22]$. In the other publication dealing with $\left[\mathrm{C}_{1} \mathrm{C}_{4} \mathrm{im}^{+}\right]\left[\mathrm{NfO}^{-}\right]$and nitric acid [86], the water content of the $\left[\mathrm{C}_{1} \mathrm{C}_{4} \mathrm{im}^{+}\right]\left[\mathrm{NfO}^{-}\right] \mathrm{IL}$ phase is said to be equal to $15.8 \mathrm{wt} \%$ (starting volumes of the aqueous and IL phase are identical), a value in line with that obtained by Jensen and co-workers [85] for perchlorate salt/perchloric acid combination. We thus may expect similar volume changes. 
The question of water distribution is acknowledged by Jensen et al. [85], who state that "watersaturated $\left[\mathrm{C}_{1} \mathrm{C}_{4} \mathrm{im}^{+}\right]\left[\mathrm{NfO}^{-}\right]$would seem to have more in common with conventional concentrated salt solutions than (...) molecular organic solvents" so that "in liquid-liquid extraction systems $\left[\mathrm{C}_{1} \mathrm{C}_{4} \mathrm{im}^{+}\right]\left[\mathrm{NfO}^{-}\right]$appears to resemble an aqueous biphasic extraction system". We fully agree with that statement. However, these authors did not attempt to measure a $\mathrm{pH}$ equilibrium value in the lower phase neither did they attempt any experiments by varying the temperature.

\subsubsection{Discussion}

From the examples discussed above, it is clear that thermomorphic behavior and changes from mono to biphasic state of systems containing at least water and one IL are a rather common phenomenon and this book is a clear proof of this statement. By contrast to what could be thought it is not true that ILs for use in solvent extraction should be immiscible with water: all the examples here provided contradict this statement.

From some striking experiments discussed above [22], it seems that using the thermomorphic behavior of systems in view of metal extraction offers great advantages in terms of efficiency, easiness and duration, and therefore, cost. Gathering the knowledge of the scientific community dealing with thermomorphic behavior and salt-in/salt-out effects, on the one hand, and that working on metal extraction by use of ILs, on the other hand, would be very fruitful and a first attempt to link the fundamental aspects of the two domains was done previously by us [77]. However, examples given in Section 9.4 highlight the regrettable poor connections existing at the moment and it is one of the aims of this review chapter to bring links between them. We hope that the review of this chapter will bring the two communities closer by showing that "real" ABS have a lot aspects (if not all) in common with "classical" water-IL liquid-liquid extraction systems: water content and transfer of ions from one phase to the other are physico-chemical characteristics found in both types of systems. Addition of large amounts of acid and/or metal salts and/or extractant perturbs miscibility curves in a way quite similar in nature (if not in quantitative values) as addition of kosmotropic salts does.

\subsection{Conclusions}

Despite the obvious considerations on green aspects brought about by the use of large amounts of water and of ILs as non-volatile and non-flammable salts, one should not overlook some problems to be solved: IL-ABS of the type reviewed here are most probably difficult to handle on an industrial scale because of the large changes in respective volumes of the phases and variations of UCST/LSCT as a function of all component concentrations. Actually, an industrial goal is certainly to feed the system with a highly metal-loaded aqueous phase and to recover a highly metal-loaded lower phase. Another trouble may arise from the distribution of the IL components between the upper and lower phases which render their recovery problematic.

On a more fundamental perspective, elucidation of the extraction mechanism clearly requires a comprehensive analytical determination of ions, molecular compounds and water fluxes between the two phases. This is a great experimental challenge but it will not be of general help to our understanding of IL-ABS unless tremendous efforts are put also in the search for tractable theoretical approaches, able to describe and predict UCST/LCST and distribution ratios of all components in 
order to first design and conceive and then apply and use novel systems. Some attempts, which discussion is out of the scope of this review chapter, can be found in $[40,87,88]$.

We would like to end this chapter by further opening the door to other systems, again under the idea that the apparent barriers and frontiers existing between them and "real" IL-ABS are merely a question of personal feeling of the reader and are thus not as strict as could be envisioned at first glance. First, in this list of possible extensions, we would like to cite extraction of several lanthanides ( $\mathrm{La}, \mathrm{Ce}, \mathrm{Pr}, \mathrm{Nd}, \mathrm{Sm}, \mathrm{Eu}, \mathrm{Dy} \mathrm{Er}$ and $\mathrm{Lu}$ ) by use of molten calcium hydrate and $\left[\mathrm{A336}^{+}\right]\left[\mathrm{NO}_{3}^{-}\right]$[89]. Such systems are "border-line" in the sense that molten hydrates although containing water, by definition, cannot be considered as aqueous solutions. Nevertheless, distribution ratios in the range $100-700$ were obtained. Second, many other thermomorphic systems involving ILs exist. Of special though is the use of carbon dioxide, as a perfect "green solvent" (provided it is captured from the atmosphere and not produced on purpose). Scurto and co-workers demonstrated the feasibility of three-level systems (two meniscuses, for mixtures of IL, water and $\mathrm{CO}_{2}$ plus air interface) [90] and this could be put in parallel with metal extraction experiments by use of supercritical $\mathrm{CO}_{2}$ and ILs [91]. Another elegant idea, although may be relatively costly, is the replacement of water by a second IL. Successful extraction of $\mathrm{Co}$ (II) from biphasic systems composed of two "immiscible" ILs have already been performed [92]. Another wide field that remains to be explored for metal extraction is that of thermomorphic systems between one IL and one organic solvent (no water). Although this could be considered as a step backwards on an ecological perspective, some alcohols are not too detrimental to the environment. Numerous examples are e found for hexanol [93], butanol [87], propanol, butanol and pentanol [94], and other series of alcohols [42], among which octanol [95], for various ILs : $\left[\mathrm{C}_{1} \mathrm{C}_{6} \mathrm{im}^{+}\right]\left[\mathrm{BF}_{4}^{-}\right]$[42] but also $\left.\left[\mathrm{C}_{1} \mathrm{C}_{4} \mathrm{im}^{+}\right] \mathrm{CF}_{3} \mathrm{SO}_{2}^{-}\right]$[95], $\left[\mathrm{C}_{1} \mathrm{C}_{n} \mathrm{im}^{+}\right]\left[\mathrm{PF}_{6}^{-}\right]$[87] or rather unusual ILs [93]. Experiments can already be found for $\mathrm{Co}(\mathrm{II})$ in systems composed of either ethanol, propanol or butanol and nitrile-bearing functionalized ILs, which display UCST values in the range $25^{\circ} \mathrm{C}-100{ }^{\circ} \mathrm{C}$ [96]. Other thermomorphic systems comprise $\left[\mathrm{C}_{1} \mathrm{C}_{n} \mathrm{im}^{+}\right]\left[\mathrm{Tf}_{2} \mathrm{~N}^{-}\right](n=2,4,6,8,10)$ and arenes [97], while $\mathrm{CHCl}_{3}$ or mixtures $\left(\mathrm{CCl}_{4}+\mathrm{CHCl}_{3}\right)$ combined with $\left[\mathrm{C}_{1} \mathrm{C}_{n} \mathrm{im}^{+}\right]\left[\mathrm{Tf}_{2} \mathrm{~N}^{-}\right](n=4,5)$ display rather unusual miscibility curves [98]. Going a step further, we think more complex systems are also worth of notice: Systems with four phases (three meniscuses at the same time before liquid/air interface, two ILs and two organic solvents) have been studied by the Seddon group [99], showing that, as already stressed for one-meniscus systems, ions distribute independently from each other [92]. Finally, the circle comes back around with extraction experiments for rare-earth group separation by use of water, polymer, ammonium sulfate and an organic solvent, Cyanex 272 [100]: this system mixes "oldfashioned ABS" (water, PEG and salt), and "new comers" as ILs and organic solvents. Although extraction ratios are not very high, there are good chances that efficiencies will be enhanced by optimization of the overall system.

As one can see, the scientific playground is very broad. Enjoy! 


\section{Chemical chart of compounds cited in this chapter:}

$\left[\mathrm{chol}^{+}\right]\left[\mathrm{Hfac}^{-}\right]$<smiles>C[N+](C)(C)CCO</smiles>

$\left[\right.$ Hbet $\left.^{+}\right]\left[\mathrm{Tf}_{2} \mathrm{~N}^{-}\right]$<smiles>C[N+](C)(C)CC(=O)O</smiles>

Bet<smiles>C[N+](C)(C)CC(=O)[O-]</smiles>

$\left[\mathrm{chol}^{+}\right]\left[\mathrm{Tf}_{2} \mathrm{~N}^{-}\right]$<smiles>C[N+](C)(C)CCO</smiles>

$\left[\mathrm{C}_{1} \mathrm{C}_{1} \mathrm{C}_{8} \mathrm{im}^{+}\right]$

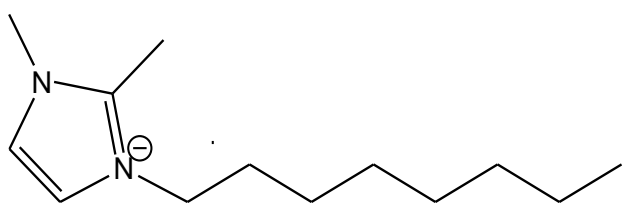

$\left[\mathrm{C}_{1} \mathrm{C}_{1} \mathrm{C}_{8}\right.$ pirid $\left.^{+}\right]$<smiles>CCCCCCCC[n+]1cc(C)cc(C)c1</smiles>

$\left[\mathrm{C}_{1} \mathrm{C}_{8}\right.$ pyrro $\left.{ }^{+}\right]$<smiles>CCCCCCCC[N+]1(C)CCCC1</smiles> 
$\left[\mathrm{TMPA}^{+}\right]\left[\mathrm{Tf}_{2} \mathrm{~N}^{-}\right]$

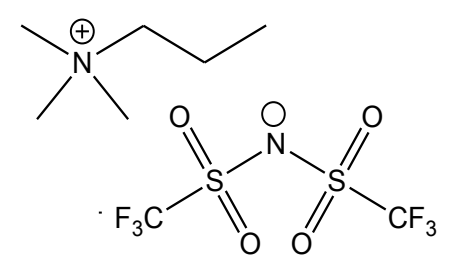

$\left[\mathrm{H}^{+}\right]\left[\mathrm{TTA}^{-}\right]$<smiles>O=C(CC(=O)C(F)(F)F)c1cccs1</smiles>

$\left[\mathrm{C}_{12}\left(\mathrm{C}_{1} \text { im }\right)_{2}{ }^{2+}\right]$

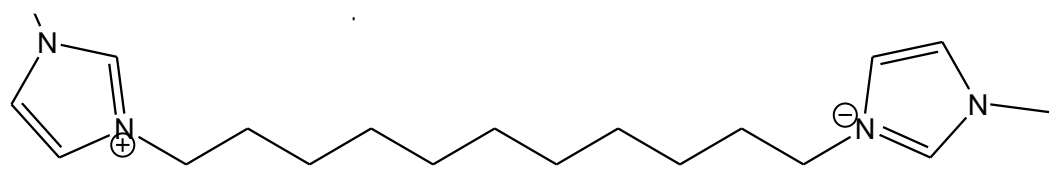

[TBA ]

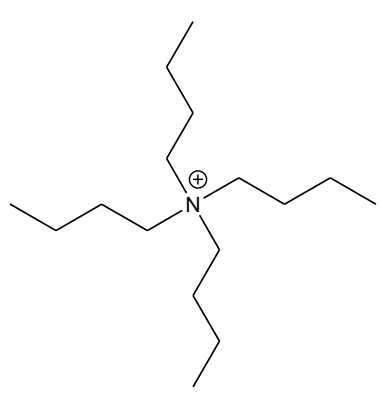

$\left[\mathrm{A} 336^{+}\right]\left[\mathrm{Cl}^{-}\right]$is a mixture of:

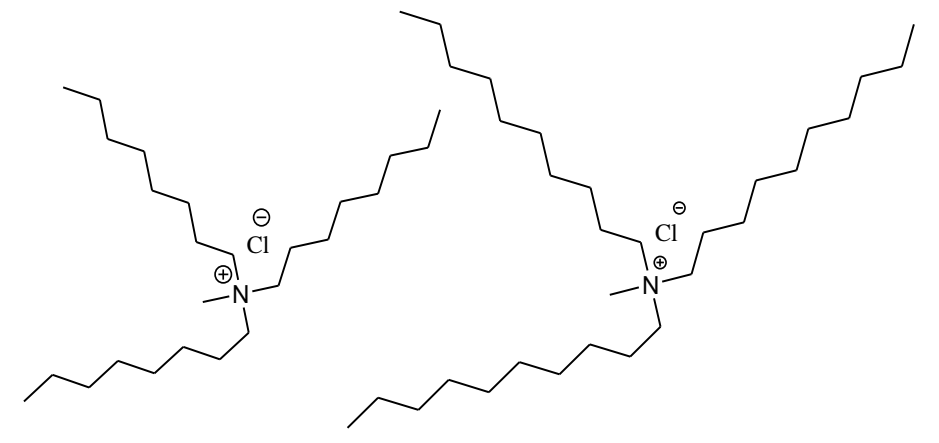


Cyanex 272

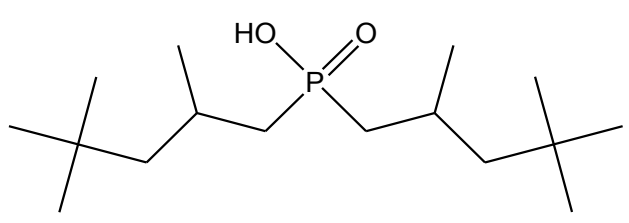

$[\mathrm{DEHP}]$ and $\left[\mathrm{P}_{444} \mathrm{E}_{n}^{+}\right](n=1,2,3)$<smiles>CCCCC(CC)COP(=O)([O-])OCC(CC)CCCC</smiles><smiles>CCCCC(CCCC)(CCCC)CCOC</smiles><smiles>CCCCC(CCCC)(CCCC)CCOCCOC</smiles><smiles>CCCCP(CCCC)(CCCC)(CCCC)CCOCCOCCOC</smiles> 


\section{References}

[1] Solvent extraction : principles and practice, 2nd ed ed., Marcel dekker, New York, 2004.

[2] Dai S, Yu YH, Barnes CE, (1999) Solvent extraction of strontium nitrate by a crown ether using room temperature ionic liquids. J. Chem. Soc., Dalton Trans. 1201.

[3] Stojanovic A, Keppler BK, (2012) lonic liquids as extracting agents for heavy metals. Sep. Sci. Technol. 47:189-203.

[4] Billard I, Ionic liquids: new hopes for efficient lanthanide/actinide extraction and separation?, in: J.C.G. Bünzli, V.K. Percharsky (Eds.) Handbook on the Physics and Chemistry of Rare Earths, Elsevier, 2013.

[5] Sun X, Luo H, Dai S, (2012) lonic liquids based extraction: a promising strategy for the advanced nuclear fuel cycle. Chem. Rev. 112:2100-2128.

[6] Kolarik Z, (2013) lonic liquids: how far do they extend the potential of solvent extraction of $f$ elements ? Solv. Ext. Ion Exchange 31:24-60.

[7] Messadi A, Mohamadou A, Boudesocque S, Dupont L, Guillon E, (2013) Task-specific ionic liquid with coordinating anion for heavy metal ion extraction: cation exchange versus ion-pair extraction. Sep. Pur. Technol. 107:172-178.

[8] Mohapatra PK, Kandwal P, Iqbal M, Huskens J, Murali MS, Verboom W, (2013) A novel CMPOfunctionalized task specific ionic liquid: synthesis, extraction and spectroscopic investigations of actinide and lanthanide complexes. Dalton Trans. 42:4343-4347.

[9] Egorov VM, Djigailo DI, Momotenko DS, Cheryshov DV, Torocheshnikova II, Sirnova SV, Pletnev IV, (2010) Task-specific ionic liquid trioctylmethylammonium salicylate as extraction solvent for transition metal ions. Talanta 80:1177-1182.

[10] Visser AE, Swatloski RP, Reichert WM, Mayton R, Sheff S, Wierzbicki A, Davis JH, Rogers RD, (2002) Task-specific ionic liquids incorporating novel cations for the coordination and extraction of $\mathrm{Hg} 2+$ and $\mathrm{Cd} 2+$ : synthesis, chacterization and extraction studies. Envir. Sci. Technol. 36:2523.

[11] Luo H, Dai S, Bonnesen PV, Buchanan AC, (2006) Separation of fission products based on ionic liquids: task specific ionic liquids containing an aza-crown ether fragment. J. Alloys. Compds. 418:195. [12] Vaezzadeh M, Shemirani F, Majidi B, (2012) Determination of silver in real samples using homogeneous liquid-liquid microextraction based on ionic liquid. J. Anal. Chem. 67:28-34.

[13] Gosh K, Maiti M, Lahiri S, Hussain VA, (2014) Ionic liquid-salt based aqueous biphasic system for separation of $109 \mathrm{Cd}$ from silver target. J. Radioanal. Nucl. Chem. 302:925-930.

[14] Papaiconomou N, Vite G, Goujon N, Levêque JM, Billard I, (2012) Efficient removal of gold complexes from water by precipitation or liquid-liquid extraction using ionic liquids. Green Chem. 14:2050-2056.

[15] Zuo, Y., Liu, Y., Chen, J., Li, Q. D, (2008) The separation of Cerium(IV) from nitric acid solutions containing thorium(IV) and lanthanides(III) using pure [C8mim]PF6 as extracting phase. Ind. Eng. Chem. Res. 47:2349.

[16] Vander-Hoogerstraete T, Onghena B, Binnemans K, (2013) Homogeneous liquid-liquid extraction of metal ions with a functionalized ionic liquid. J. Phys. Chem. Lett. 4:1659-1663.

[17] Blesic M, Gunaratne HQN, Jacquemin J, Nockemann P, Olejarz S, Seddon KR, Strauss CR, (2014) Tunable thermomorphism and applications of ionic liquid analogues of Girard's reagents. Green Chem. 16:4115-4121.

[18] Depuydt D, Liu L, Glorieux C, Dehaen W, Binnemans K, (2015) Homogeneous liquid-liquid extraction of metal ions with non-fluorinated bis(ethylhexyl)phosphate ionic liquids having a lower critical solution temperature in combination with water. Chem. Commun. 51:14183-14186.

[19] Akama Y, Sali A, (2002) Extraction mechanism of $\operatorname{Cr}(\mathrm{IV})$ on the aqueous two-phase system of tetrabutylammonium bromide and (NH4)2SO4 mixture. Talanta 57:681-686.

[20] Xie ZL, Taubert A, (2011) Thermomorphic behavior of the ionic liquids [C4mim] [FeCl4] and [C12mim][FeCl4]. Chem. Phys. Chem. 12:364-368.

[21] Papaiconomou N, Billard I, Chainet E, (2014) Extraction of iridium from aqueous solutions using hydrophilic/hydrophobic ionic liquids. RSC Advances 4:48260-48266. 
[22] Vander-Hoogerstraete T, Onghena B, Binnemans K, (2013) Homogeneous liquid-liquid extraction of rare earths with the betaine-betainium(trifluoromethylsulfonyl)imide ionic liquid system. Int. J. Mol. Sci. 14:21353-21377.

[23] Onghena B, Jacobs J, Meervelt LV, Binnemans K, (2014) Homogeneous liquid-liquid extraction of neodymium(III) by choline hexafluoroacetylacetonate in the ionic liquid choline bis(trifluoromethylsulfonyl)imide. Dalton Trans. 43:11566-11578.

[24] Onghena B, Opsomer T, Binnemans K, (2015) Separation of cobalt and nickel using a thermomorphic ionic-liquid-based aqueous biphasic system. Chem. Commun. 51:15932-15935.

[25] Sasaki K, Takao K, Suzuki T, Mori T, Arai T, Ikeda Y, (2014) Extraction of Pd(II), Rh(III) and Ru(III) from $\mathrm{HNO} 3$ aqueous solution to betainium bis(trifluoromethanesulfonyl)imide ionic liquid. Dalton Trans. 43:5648-5661.

[26] Génand-Pinaz S, Papaiconomou N, Leveque JM, (2013) Removal of platinium from water by precipitation or liquid-liquid extraction and separation from gold using ionic liquids. Green Chem. 15:2493-2501.

[27] Depuydt D, Dehaen W, Binnemans K, (2015) Solvent extraction of scandium(III) by an aqueous biphasic system with a nonfluorinated functionalized ionic liquid. Ind. Eng. Chem. Res. 54:8988-8996.

[28] Bridges NJ, Rogers RD, (2008) Can kosmotropic salt/chaotropic ionic liquid (salt/salt aqueous biphasic systems) be used to remove pertechnetate from complex salt waste? Sep. Sci. Technol. 43:1083-1090.

[29] Sasaki K, Suzuki T, Mori T, Arai T, Takao K, Ikeda Y, (2014) Selective liquid-liquid extraction of uranyl species using task-specific ionic liquid, betainium bis(trifluoromethylsulfonyl)imide. Chem. Lett.

[30] Ohno H, Electrochemical aspects of ionic liquids, Wiley, 2005.

[31] Wasserscheid, P., Welton, T., lonic liquids in synthesis, Wiley-VCH, Weinheim, 2008.

[32] Scammells, J. P, Scott, L. J, Singer, D. R, (2005) lonic liquids: the neglected issues. Aust. J. Chem. 58:155-169.

[33] Weingartner $\mathrm{H},(2008)$ Understanding ionic liquids at the molecular level: facts, problems and controversies. Angew. Chem. Int. Ed. 47:654-670.

[34] Chiappe C, (2007) Nanostructural organization of ionic liquids: theoretical and experimental evidences of the presence of well defined local structures in ionic liquids. Monatsh Chem. 138:1035.

[35] Freire MG, Claudio AFM, Araujo JMM, Coutinho JAP, Marrucho IM, Lopes JNC, Rebelo LPN, (2012) Aqueous biphasic systems: a boost brougth about using ionic liquids. Chem. Soc. Rev. 41:4966-4995.

[36] Kohno Y, Arai H, Ohno H, (2011) Dual stimuli-responsive phase transition of an ionic liquid/water mixture. Chem. Commun. 47:4772-4774.

[37] Rebelo LPN, Najdanovic-Visak V, Visak ZP, Ponte MNd, Szydlowski J, Cerdeirina CA, Troncoso J, Romani L, Esperança JMSS, Guedes HJR, Sousa HCd, (2004) A detailed thermodynamic analysis of [C4mim][BF4] + water as a case study to model ionic liquid aqueous solutions. Green Chem. 6:369.

[38] Suarez PAZ, Einloft S, Dullius JEL, Souza RFd, Dupont J, (1998) Synthesis and physical-chemical properties of ionic liquids based on 1-n-butyl-3-methylimidazolium cation. J. Chim. Phys. 95:16261639.

[39] Fukaya Y, Ohno H, (2013) Hydrophobic and polar ionic liquids. Phys. Chem. Chem. Phys. 15:40664072.

[40] Wagner M, Stanga O, Schroer W, (2003) Corresponding states analysis of the critical points in binary solutions of room temperature ionic liquids. Phys. Chem. Chem. Phys. 5:3943-3950.

[41] Najdanovic-Visak V, Esprança JMSS, Rebelo LPN, Ponte MNd, Guedes HJR, Seddon KR, Sousa HCd, Szydlowski J, (2003) Pressure, isotope and water co-solvent effects in liquid-liquid equilibria of (ionic liquid + alcohol) systems. J. Phys. Chem. B 107:12797-12807.

[42] Wagner M, Stanga O, Schroer W, (2004) The liquid-liquid coexistence of binary mixtures of the room temperature ionic liquid 1-methyl-3-hexylimidazolium tetrafluoroborate with alcohols. Phys.

Chem. Chem. Phys. 6:4421-4431. 
[43] Kohno Y, Ohno H, (2012) Temperature-responsive ionic liquid/water interfaces: relation between hydrophilicity of ions and dynamic phase change. Phys. Chem. Chem. Phys. 14:5063-5070.

[44] Nockemann P, Binnemans K, Thijs B, Parac-Vogt TN, Merz K, Mudring AV, Menon PC, Rajesh RN, Cordoyiannis G, Thoen J, Leys J, Glorieux C, (2009) Temperature-driven mixing demixing behavior of binary mixtures of the ionic liquid choline bis(trifluoromethylsulfonyl)imide and water. J. Phys. Chem. B 113:1429-1437.

[45] Fukaya Y, Sekikawa K, Murata K, Nakamura N, Ohno H, (2007) Miscibility and phase behavior of water-dicarboxylic acid type ionic liquid mixed systems. Chem. Commun. 3089-3091.

[46] Wang R, Leng W, Gao Y, Yu L, (2014) microemulsion-like aggregation behaviour of an LCST-type ionic liquid in water. RSC Advances 4:14055-14062.

[47] Trindade JR, VIsak ZP, Blesic M, Marrucho IM, Coutinho JAP, Lopes JNC, Rebelo LPN, (2007) Salting-out effects in aqueous ionic liquid solutions: cloud point temperature shifts. J. Phys. Chem. B 111:4737-4741.

[48] Shahriari S, Tomé LC, Araujo JMM, Rebelo LPN, Coutinho JAP, Marrucho IM, Freire MG, (2013) Aqueous biphasic systems: a benign route using cholinium-based ionic liquids. RSC Advances 3:18351843.

[49] Merchuk JC, Andrews BA, Asenjo JA, (1998) Aqueous two-phase systems for protein separation studies on phase inversion. J Chromatography B 711:285-293.

[50] Kaul A, Pereira RAM, Asenjo JA, Merchuk JC, (1995) Kinetics of phase separation for polyethylene glycol-phosphate two phase systems Biotechnology and Bioengineering 48:246-256.

[51] Gutowski KE, Broker GA, Willauer HD, Huddleston JG, Swatloski RP, Holbrey JD, Rogers RD, (2003) Controlling the aqueous miscibility of ionic liquids: aqueous biphasic systems of watermiscible ionic liquids and water-structuring salts for recycle, methatesis and separations. J. Am. Chem. Soc. 125:6632.

[52] Neves CMSS, Ventura SPM, Freire MG, Marrucho IM, Coutinho JAP, (2009) Evaluation of cation influence on the formation and extraction capability of ionic-liquid-based aqueous biphasic systems. J. Phys. Chem. B 113:5194-5199.

[53] Dupont D, Depuydt D, Binnemans K, (2015) Overview of the effect of salts on biphasic ionic liquid/water solvent extraction systems: anion exchange, mutual solubility and thermomorphic properties. J. Phys. Chem. B 119:6747-6757.

[54] Fagnant DP, Goff GS, SCott BL, Runde W, Brenecke JF, (2013) Switchable phase behavior of [HBet][Tf2N]-H2O upon neodymium loading: implications for lanthanide separations. Inorg. Chem. 52:549-551.

[55] Kohno Y, Ohno H, (2012) Ionic liquid/water mixtures: from hostility to conciliation. Chem. Commun. 48:7119-7130.

[56] Yoshida Y, Saito G, (2010) Design of functional ionic liquids using magneto and luminescent active ions. Phys. Chem. Chem. Phys. 12:1675.

[57] Lecocq V, Graille A, Santini C, Baudouin A, Chauvin Y, Basset JM, Arzel L, Bouchu D, Fenet B, (2005) Synthesis and characterization of ionic liquids based upon 1-butyl-2,3-dimethylimidazolium chloride/ZnCl2. New J. Chem. 29:700-706.

[58] Nockemann P, Thijs B, Pittois S, Thoen J, Glorieux C, Hecke KV, Meervelt LV, Kirchner B, Binnemans K, (2006) Task-Specific ionic liquid for solubilizing metal oxides. J. Phys. Chem. B 110:20978-20992.

[59] Brooks NR, Schaltin S, Hecke KV, Meervelt LV, Fransaer J, Binnemans K, (2012) Heteroleptic silver-containing ionic liquids. Dalton Trans. 41:6902-6905.

[60] Lee SH, Ha SH, Ha SS, Jin HB, You CY, Koo YM, (2007) Magnetic behavior of mixture of magnetic ionic liquid [bmim] FeCl4 and water. J. Appl. Phys. 101:09J102-101-109J102-103.

[61] Onghena B, Binnemans K, (2015) Recovery of scandium(III) from aqueous solutions by solvent extraction with the functionalized ionic liquid betainium bis(trifluoromethylsulfonyl)imide. Ind. Eng. Chem. Res. 54:1887-1898. 
[62] Dupont D, Binnemans K, (2015) Recycling of rare earths from NdFeB magnets using a combined leaching/extraction system based on the acidity and thermomorphism of the ionic liquid [Hbet][Tf2N]. Green Chem. 17:2150-2163.

[63] Nockemann P, Thijs B, Parac-Vogt TN, Hecke KV, Meervelt LV, Tinant B, Hartenbach I, Schleid T, Ngan VT, Nguyen MT, Binnemans K, (2008) Carboxyl-functionalized task-specific ionic liquids for solubilizing metal oxides. Inorg. Chem. 47:9987-9999.

[64] Akama Y, Ito M, Tanaka S, (2000) Selective separation of cadmium from cobalt copper, iron(III) and zinc by water-based two-phase system of tetrabutylammonium bromide. Talanta 53:645-650.

[65] Atanassova M, Billard I, (2014) Determination of pKalL values of three chelating extractants in ILs. Consequences on extraction processes of 4 f-elements. J. Sol. Chem. in press.

[66] Choi YH, S.Song Y, Kim DH, (2010) Droplet-based microextraction in the aqueous two-phase system. J. Chrom. A 1217:3723-3728.

[67] Zhou Q, Bai H, Xie G, Xiao J, (2008) Temperature-controlled ionic liquid dispersive liquid phase micro-extraction. J. Chromatography A 1177:43-49.

[68] Hardt S, Hahn T, (2012) Microfluidics with aqueous two-phase systems. Lab on a Chip 12:434.

[69] Bridges NJ, Gutowski KE, Rogers RD, (2007) Investigation of aqueous biphasic systems formed from solutions of chaotropic salts with kosmotropic salts (salt-salt ABS). Green Chem. 9:177-183.

[70] Claudio AFM, Ferreira A, Shahriari S, Freire MG, Coutinho JAP, (2011) Critical assessement of the formation of ionic liquid based aqueous two phase systems in acidic media. J. Phys. Chem. B 115:11145-11153.

[71] Harjani JR, Friscic T, MacGillivray LR, Singer RD, (2008) Removal of metal ions from aqueous solutions using chelating task-specific ionic liquids. Dalton Trans. 4595.

[72] Papaiconomou N, Svecova L, Bonnaud C, Cathelin L, Billard I, Chainet E, (2015) Possibilities and limitations in separating $\mathrm{Pt}(\mathrm{IV})$ from $\mathrm{Pd}(\mathrm{II})$ combining imidazolium and phosphonium ionic liquids. Dalton Trans. 44:20131-20138.

[73] Ando T, Kohno Y, Nakamura N, Ohno H, (2013) Introduction of hydrophilic groups onto the ortho-position of benzoate anions induced phase separation of the corresponding ionic liquids with water. Chem. Commun. 49:10248-10250.

[74] Billard I, Gaillard C, (2009) Actinide and lanthanide speciation in imidazolium-based ionic liquids. Radiochim. Acta 97:355-359.

[75] Rout A, Binnemans K, (2014) Liquid-liquid extraction of europium(III) and other trivalent rareearth ions using a non-fluorinated functionnalized ionic liquid. Dalton Trans. 43:1862-1872.

[76] Gaillard C, Mazan V, Georg S, Klimchuk O, Sypula M, Billard I, Schurhammer R, Wipff G, (2012) Acid extraction to a hydrophobic ionic liquid: the role of added tributylphosphate investigated by experiments and simulations. Phys. Chem. Chem. Phys. 14:5187-5199.

[77] Mazan V, Billard I, Papaiconomou N, (2014) Experimental connections between aqueous aqueous and aqueous ionic liquid biphasic systems. RSC Advances 4:13371-13384.

[78] Neves CMSS, Freire MG, Coutinho JAP, (2012) Improved recovery of ionic liquids from contaminated aqueous streams using aluminium-based salts. RSC Advances 2:10882-10890.

[79] Freire MG, Carvalho PJ, Gardas RL, Marrucho IM, Santos LMNBF, Coutinho JAP, (2008) Mutual solubilities of water and the [Cnmim][Tf2N] hydrophobic ionic liquids. J. Phys. Chem. B 112:16041610.

[80] Billard I, Ouadi A, Gaillard C, (2013) Is a universal model to describe liquid:liquid extraction of cations by use of ionic liquid at reach ? Dalton Trans. 42:6203-6212.

[81] Bonnaffé-Moity M, Ouadi A, Mazan V, Miroshnichenko S, Ternova D, Georg S, Sypula M, Gaillard C, Billard I, (2012) Comparison of uranyl extraction mechanisms in ionic liquid by use of malonamide or malonamide-functionalized ionic liquid. Dalton Trans. 41:7526-7536.

[82] Sypula M, Ouadi A, Gaillard C, Billard I, (2013) Kinetics of metal extraction in ionic liquids: Eu3+/HNO3//TODGA/C1C4imTf2N as a case study. RCS Advances 3:10736-10744.

[83] Abulhassani J, Manzoori JL, Amjadi M, (2010) Hollow fiber based liquid phase microextraction using ionic liquid solvent for preconcentration of lead and nickel from environmental and biological 
samples prior to determination by electrothermal atomic absorption spectrometry. J. Hazardous Mat. 176:481-486.

[84] Dadfarnia S, Shabani AMH, Bidabadi MS, Jafari AA, (2010) A novel ionic liquid/micro-volume back extraction procedure combined with flame atomic absorption spectrometry for determination of trace nickel in samples of nutritional interest. J. Hazardous Mat. 173:534-538.

[85] Jensen MP, Borkowski M, Lazak I, Beitz JV, Rickert PG, Dietz ML, (2012) Anion effects in the extraction of lanthanide 2-thenoyltrifluoroacetone complexes into an ionic liquid. Sep. Sci. Technol. 47:233-243.

[86] Kozonoi, N., Ikeda, Y., (2007) Extraction mechanism of metal ion from aqueous solution to the hydrophobic ionic liquid 1-butyl3-methylimidazolium nonafluorobutanesulfonate. Monatsh. Chem. 138:1145.

[87] Wu CT, Marsh KN, Deev AV, Boxall JA, (2003) Liquid-liquid equilibria of room temperature ionic liquids and butan-1-ol. J. Chem. Eng. Data 48:486-491.

[88] Jin X, Held C, Sadowski G, (2013) Modeling imidazolium-based ionic liquids with ePC-SAFT. Fluid Phase Equilibria 335:64-73.

[89] Rout A, Binnemans K, (2014) Separation of rare earths from transition metals by liquid-liquid extraction from a molten salt hydrate to an ionic lquid phase. Dalton Trans. 43:3186-3195.

[90] Scurto AM, Aki SNVK, Brennecke JF, (2003) Carbon dioxide induced separation of ionic liquids and water. Chem. Commun. 572.

[91] Mekki S, Wai CM, Billard I, Moutiers G, Yen CH, Wang JS, Ouadi A, Gaillard C, Hesemann P, (2005) $\mathrm{Cu}(\mathrm{II})$ extraction by supercritical fluid carbon dioxide from a room temperature ionic liquid using fluorinated $\beta$-diketones. Green Chem. 7:421.

[92] Wellens S, Thijs B, Möller C, Binnemans K, (2013) Separation of cobalt and nickel by solvent extraction with two mutually immiscible ionic liquids. Phys. Chem. Chem. Phys. 15:9663-9669.

[93] Riisager A, Fehrmann R, Berg RW, Hal Rv, Wasserscheid P, (2005) Thermomorphic phase separation in ionic liquid-organic liquid systems: conductivity and spectroscopic characterization. Phys. Chem. Chem. Phys. 7:3052-3058.

[94] Heintz A, Lehmann JK, Wertz C, (2003) Thermodynamic properties of mixtures containing ionic liquids. 3. Liquid-liquid equilibria of binary mixtures of 1-ethyl-3-methylimidazolium bis(trifluoromethylsulfonyl)imide with propan-1-ol, butan-1-ol and pentan-1-ol. J. Chem. Eng. Data 48:472-474.

[95] Crosthwaite JM, Aki SNVK, Maginn EJ, Brennecke JF, (2004) Liqid phase behavior of imidazoliumbased ionic liquids with alcohols. J. Phys. Chem. B 108:5113-5119.

[96] Nockemann P, Pellens M, Hecke KV, Meervelt LV, Wouters J, Thijs B, Vanecht E, Parac-Vogt T, Mehdi H, Schaltin S, Fransaer J, Zahn S, Kirchner B, Binnemans K, (2010) Cobalt(II) complexes of nitrile-functionalized ionic liquids. Chem. Eur. J. 16:1849-1858.

[97] Lachwa J, Szydlowski J, Makowska A, Seddon KR, Esperança JMSS, Guedes HJR, Rebelo LPN, (2006) Changing from an unusual high temperature demixing to a UCST-type in mixtures of 1-alkyl-3methylimidazolium bis(trifluoromethylsulfonyl)amide and arenes. Green Chem. 8:262-267.

[98] Lachwa J, Szydlowski J, Najdanovic-Visak V, Rebelo LPN, Seddon KR, Ponte MNd, Esperanca JMSS, Guedes HJR, (J2005) Evidence for lower critical solution behavior in ionic liquid solutions. J. Am. Chem. Soc. 127:6542-6543.

[99] Arce A, Earle MJ, Katdare SP, Rodriguez H, Seddon KR, (2006) Mutually immiscible ionic liquids. Chem. Commun. 2548-2550.

[100] Sui N, Huang K, Zhang C, Wang N, Wang F, Liu H, (2013) light middle and heavy rare earth group separation: a new approach via a liquid-liquid three phase system Ind. Eng. Chem. Res. 52:59976008. 